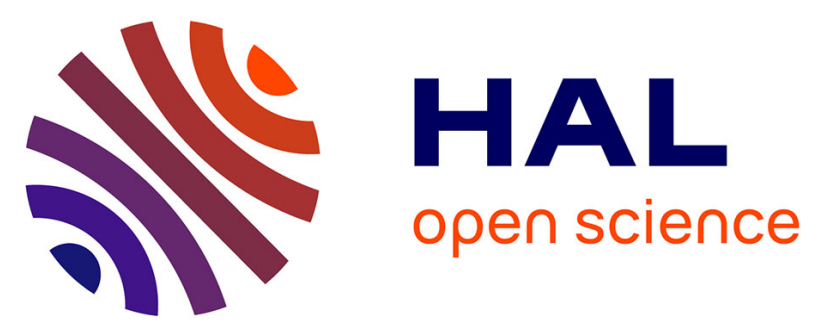

\title{
The influence of shearable and nonshearable precipitates on the Portevin-Le Chatelier behavior in precipitation hardening AlMgScZr alloys
}

Han Chen, Zhe Chen, G Ji, Shengyi Zhong, Haowei Wang, András Borbély, Yubin Ke, Yves Bréchet

\section{To cite this version:}

Han Chen, Zhe Chen, G Ji, Shengyi Zhong, Haowei Wang, et al.. The influence of shearable and nonshearable precipitates on the Portevin-Le Chatelier behavior in precipitation hardening AlMgScZr alloys. International Journal of Plasticity, 2021, 147, pp.103120. 10.1016/j.ijplas.2021.103120 . hal03370763

\section{HAL Id: hal-03370763 \\ https://hal.science/hal-03370763}

Submitted on 8 Oct 2021

HAL is a multi-disciplinary open access archive for the deposit and dissemination of scientific research documents, whether they are published or not. The documents may come from teaching and research institutions in France or abroad, or from public or private research centers.
L'archive ouverte pluridisciplinaire HAL, est destinée au dépôt et à la diffusion de documents scientifiques de niveau recherche, publiés ou non, émanant des établissements d'enseignement et de recherche français ou étrangers, des laboratoires publics ou privés. 
The influence of shearable and nonshearable precipitates on the Portevin-Le Chatelier behavior in precipitation hardening

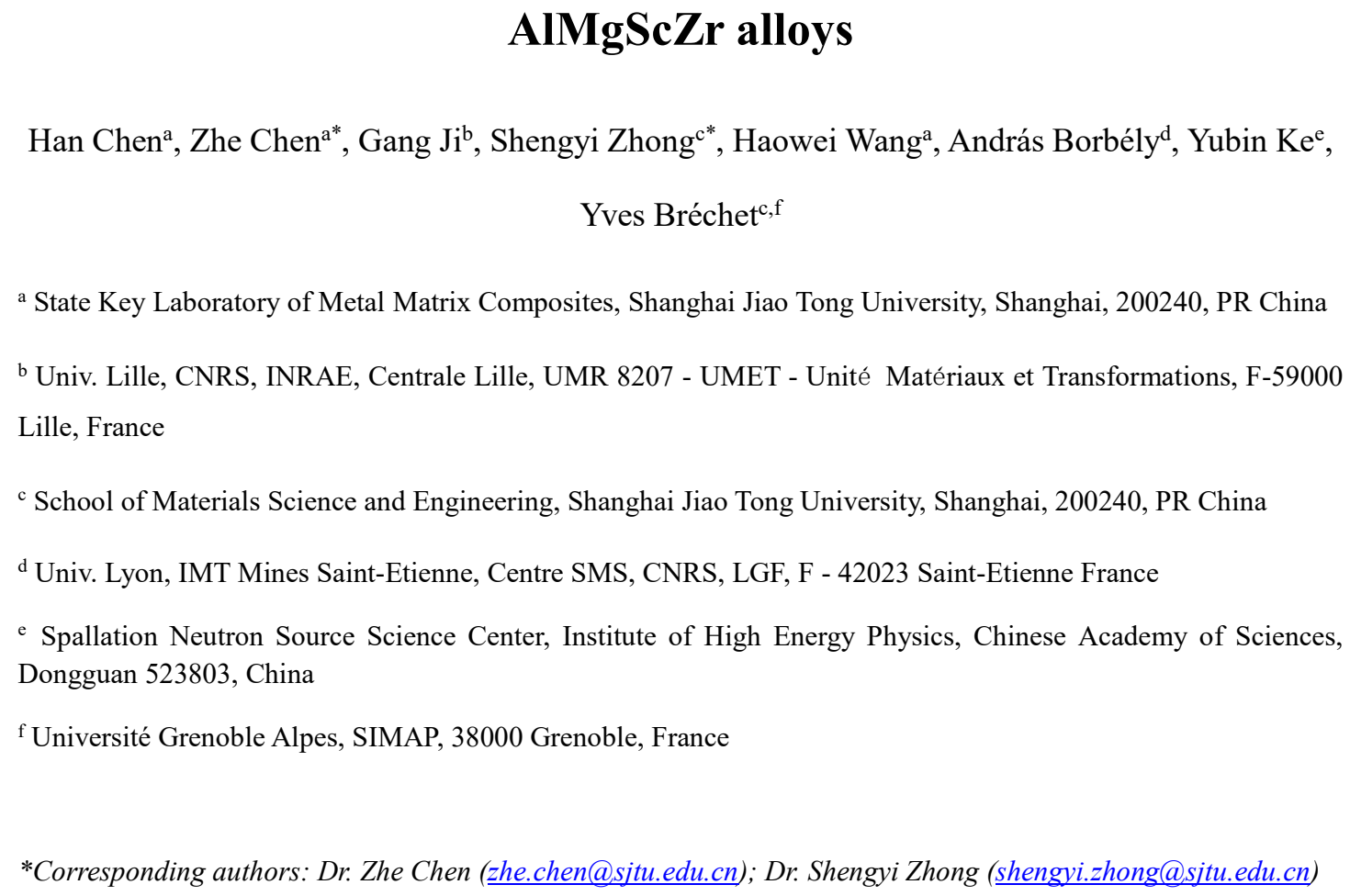

Abstract: The well-known mechanisms of interaction between precipitates and dislocations are shearing (for shearable precipitates) and bypassing mechanisms (for nonshearable precipitates). The transition from shearable to nonshearable precipitates in precipitation hardening alloys leads to changes of dislocation motion mode and dislocation multiplication behavior, which inevitably causes different PLC behaviors. In this study, we systematically investigate the influence of shearable and nonshearable $\mathrm{Al}_{3}(\mathrm{Sc}, \mathrm{Zr})$ precipitates on PLC behaviors by experimental characterization for precipitation hardening AlMgScZr alloys. We analyze the onset strain, critical strain-rate range, serration amplitude, and propagation behavior of PLC bands in detail for AlMgScZr alloys with shearable and nonshearable precipitates, respectively. We find that the transition from shearable to nonshearable precipitates changes the PLC band propagation behavior, decreases the magnitude of serration amplitude, expands the strain-rate range as well as decreases the critical strain rate between normal behavior (the critical strain increases with the increase of strain rate) 
and inverse behavior (the critical strain decreases with the increase of strain rate) regimes due to the different dislocation-precipitate interactions. Besides, the transition from shearable to nonshearable precipitates increases the onset strain at normal behavior while decreases the onset strain at inverse behavior depending on the different roles of precipitates in the solute-dislocation interaction. Finally, we reveal the nature of influence of different dislocation-precipitate interactions on PLC behavior considering different strengthening mechanisms based on quantitative characterization on precipitates and dislocation density.

\section{Keywords: Aluminium alloy, Precipitates, Portevin-Le Chatelier effect, Strengthening mechanism, Dislocations}

\section{Introduction}

Portevin-Le Chatelier (PLC) is a kind of dynamic strain ageing (DSA) phenomenon due to the interaction between diffusing solute atoms and mobile dislocations, which has been found in many alloy systems, particularly in AlMg alloys [McCormick, 1972a; Van den Beukel, 1975; Estrin and Kubin, 1990; Kubin and Estrin, 1990; Robinson, 1994; Hähner, 1997; Lebyodkin et al., 2000; Picu, 2004; Fressengeas et al., 2005; Antolovich and Armstrong, 2014; Aboulfadl et al., 2015; Swaminathan et al., 2015; Zhang et al., 2017; Tsai et al., 2019]. On the atomic level, the PLC phenomenon is caused by the diffusion of solute atoms [Cottrell and Bilby, 1949; Yoshinaga and Morozumi, 1971a, 1971b; Aifantis, 1987; Estrin and Kubin, 1990; Picu, 2004; Curtin et al., 2006; Soare and Curtin, 2008a, 2008b; Aboulfadl et al., 2015]. The dislocations are efficiently pinned by solutes in direct relation with the solute which has segregated to its core. The longer the waiting time (i.e. the lower the imposed strain rate) of a dislocation between two jumps, the higher the solute concentration at dislocation core and therefore the higher the resulting flow stress [McCormick, 1972a; Estrin and Kubin, 1990, 1991, 1995; Kubin and Estrin, 1985, 1990; Curtin et al., 2006]. The interaction between dislocations and solute atoms can result in a decrease of the flow stress associated to an increase of the imposed strain rate and thus to a negative strain rate sensitivity (SRS) [Van den Beukel, 1975; Mulford and Kocks, 1979; Louat, 1981; Kubin et al., 1988; Estrin and Kubin, 1990, 
1995; Kubin and Estrin, 1990; Picu, 2004; Curtin et al., 2006]. On a macroscopic scale, the PLC phenomenon is generally manifested by sudden localizations of the plastic strain in transient deformation bands, leading to jerky flow features on the stress strain curves [Zhang et al., 2001; Kok et al., 2003; Zhang et al., 2005; Benallal et al., 2008; Zavattieri et al., 2009; Manach et al., 2014; Klusemann et al., 2015; Shibkov et al., 2016; Yuzbekova et al., 2017; Yang et al., 2018; Zhemchuzhnikova et al., 2018; Ren et al., 2021]. When PLC occurs, each serration of the deformation curve corresponds to the development of localized deformation bands [Klusemann et al., 2015; Yuzbekova et al., 2017; Zhemchuzhnikova et al., 2018]. The nucleation and propagation of deformation bands have been proved to have a close relation to jerky flow for many materials with PLC behavior, especially in AlMg alloys [Zhang et al., 2001; Ait-Amokhtar et al., 2006a, 2006b; Zavattieri et al., 2009; Manach et al., 2014; Klusemann et al., 2015; Yang et al., 2018]. Three major types of PLC bands, namely continuous propagating type $\mathrm{A}$, hopping type $\mathrm{B}$ and non-propagating type $\mathrm{C}$ bands are defined based on the serrated curves [Pink and Grinberg, 1981; Robinson and Shaw, 1994; Jiang et al., 2007; Yilmaz, 2011; Hu et al., 2012; Zhang et al., 2017].

The PLC bands generated during deformation leave undesirable traces on the surface of sheet products during deep drawing restricting the commercial application of some alloys [Dierke et al., 2007; Böhlke et al., 2009; Yilmaz, 2011; Duan et al., 2021]. Moreover, the ductility will be decreased due to the appearance of PLC [Kang et al., 2006; Aretz, 2007; Halim et al., 2007; Zhang et al., 2012; Alinaghian et al., 2014; Keralavarma et al., 2014; Rousselier and Quilici, 2015]. Undoubtedly, the PLC effect is expected to be diminished by designing specific alloy compositions or by controlling processing conditions. Nanostructured precipitates are beneficial to eliminate the PLC effect, which already has been reported previously [Riley and McCormick, 1977; Hayes and Hayes, 1982, 1984; Wert and Wycliffe, 1985; Pink, 1989; Kumar and McShane, 1993; Kumar et al., 1996; Thevenet et al., 1999; Nalawade et al., 2008; Wang et al., 2016; Cai et al., 2017]. Pink and Thevenet et al. [Pink, 1989; Thevenet et al., 1999] proved that the jerky flow in AlZnMg alloy would be restrained by precipitates, especially the appearance of GP-zones could increase the onset strain of PLC significantly. Kumar and McShane [Kumar and McShane, 1993] stated that the transformation of metastable precipitates (from coherent to incoherent state) in the process of ageing can lead to the disappearance of PLC in AlLi alloys. However, some scholars underlined that solute concentration in the 
matrix decreased due to precipitation, which suppressed PLC [Riley and McCormick, 1977; Wert and Wycliffe, 1985; Nalawade et al., 2008]. There are others who emphasized that dislocations shearing of coherent precipitates directly resulted in serrations on the flow stress curve of AlLi alloys [Kumar and Pink, 1994, 1997; Kumar, 1995; Pink et al., 2000]. While some people demonstrated that dislocations shearing precipitates would not lead to jerky flow in the AlLi or in the Ni-based superalloy [Chmelík et al., 1998; Wang et al., 2016]. In the mentioned studies [Riley and McCormick, 1977; Hayes and Hayes, 1982, 1984; Wert and Wycliffe, 1985; Pink, 1989; Kumar and McShane, 1993; Kumar and Pink, 1994; Kumar et al., 1995; Kumar et al., 1996; Chmelík et al., 1998; Thevenet et al., 1999; Nalawade et al., 2008; Wang et al., 2016; Cai et al., 2017], the solute concentration in the matrix decreases when the precipitates appear, so it is difficult to distinguish whether the change of PLC behavior is caused by precipitates or solute concentration variations. Although the aforementioned works have focused on the effect of nanosized precipitates on the PLC behavior, they do not focus on the influence of precipitates on the propagation behavior of PLC bands. Only recently, Cai et al. and Wang et al. indicated that type A bands can turn into type $\mathrm{B}$, and finally became type $\mathrm{C}$ with increasing precipitate volume fraction in Ni-based alloys [Cai et al., 2015, 2017; Wang et al., 2019]. Cai et al. explained that these changes were due to a change in the plastic deformation mechanism, which turned from dislocation slip to stacking fault generation [Cai et al., 2017]. Obviously, this mechanism cannot be applied in the AlMg system of the present study. On the other hand, to the authors' knowledge, no attention is paid on the influence of precipitate size (i.e. the effect of different precipitate-dislocation interactions) on PLC behavior without considering the variation of solute concentration. This impedes drawing clear conclusions about the influence of precipitates on the PLC behavior.

The well-known mechanisms between precipitates and dislocations are shearing (for shearable precipitates) and bypassing mechanisms (for nonshearable precipitates) [Ardell, 1985; Gladman, 1999; Knipling et al., 2010, 2011; Hull and Bacon, 2011; Fan et al., 2018; Ming et al., 2018; Barnett et al., 2019; Xu et al., 2019; Chen et al., 2021]. The influence of precipitates on the PLC behavior lies in revealing the mechanisms of appearance of precipitates on existing dislocation-dislocation and dislocation-solute interactions. In view of current problems, we design the $\mathrm{AlMgScZr}$ 
alloy system with the $\mathrm{Al}_{3}(\mathrm{Sc}, \mathrm{Zr})$ precipitates on $\mathrm{AlMg}$ matrix to quantitatively study the effects of shearable and nonshearable precipitates on PLC behavior with the aid of experimental characterization in this study. The advantage of this alloy is that the solute $\mathrm{Mg}$ concentration keeps unchanged when $\mathrm{Al}_{3}(\mathrm{Sc}, \mathrm{Zr})$ precipitates occur, which avoids the influence of solute concentration variation on PLC (It is because the interaction of $\mathrm{Mg}$ atoms and dislocations is the one which leads to PLC phenomenon). The shearable and nonshearable $\mathrm{Al}_{3}(\mathrm{Sc}, \mathrm{Zr})$ precipitates can be obtained through controlling heat treatment, and their quantitative characterization can be easily obtained by transmission electron microscopy (TEM) and small angle neutron scattering (SANS) techniques due to its good uniform dispersion, spherical shape and thermal stability [Fuller et al., 2003; Clouet et al., 2006; Voorhees, 2006; Deschamps et al., 2007; Deschamps and Geuser, 2011; Chen et al., 2021]. In this study, we focus our attention on effects of different dislocation-precipitate interactions (shearing and bypassing mechanisms) on PLC behavior including propagation behavior of PLC band without considering the variation of solute concentration, which has not been reported to our knowledge. We will demonstrate the reason of the influence of dislocation-precipitate interaction on PLC behavior with considering different strengthening mechanisms based on the quantitative characterization on dislocation density measured by synchrotron radiation X-ray diffraction.

\section{Materials and methods}

Two cast AlMg and AlMgScZr alloys were used. The chemical compositions in wt.\% of $\mathrm{AlMg}$ and $\mathrm{AlMgScZr}$ are $\mathrm{Al}-5.7 \% \mathrm{Mg}$ and $\mathrm{Al}-5.4 \% \mathrm{Mg}-0.2 \% \mathrm{Sc}-0.15 \% \mathrm{Zr}$, respectively. The AlMg alloy was first homogenized at $813 \mathrm{~K}$ for $24 \mathrm{~h}$ and then extruded at $623 \mathrm{~K}$ with a ratio of $10: 1$. It is known that $\mathrm{Al}_{3}(\mathrm{Sc}, \mathrm{Zr})$ precipitates nucleate at aging temperatures higher than $598 \mathrm{~K}$ [Knipling et al., 2010, 2011], for which reason the cast $\mathrm{AlMgScZr}$ alloys were first aged at $623 \mathrm{~K}, 773 \mathrm{~K}$ for $3 \mathrm{~h}$ and at $813 \mathrm{~K}$ for $24 \mathrm{~h}$ correspondingly, with the purpose of obtaining shearable and nonshearable $\mathrm{Al}_{3}(\mathrm{Sc}, \mathrm{Zr})$ precipitates. After aging, the AlMgScZr alloys were also extruded at $623 \mathrm{~K}$ with an extrusion ratio of 10:1.

TEM samples were extracted from the AlMg and AlMgScZr extrusion specimens, which were polished mechanically, followed by electrochemical polishing by using a twin-jet polishing unit with a mixed solution of $1 / 3$ methanol and $2 / 3$ nitric acid. TEM 
experiments were carried out using a high-resolution Cs-corrected FEI Themis microscope operating at $300 \mathrm{kV}$ and a JOEM-2100F operating at $200 \mathrm{kV}$. The quantitative characterization on precipitates is necessary in the discussion of different dislocation-precipitate interactions on PLC behaviors, which was obtained by SANS. The SANS experiment was performed on the SANS instrument at China Spallation Neutron Source (CSNS) [Ke et al., 2018]. The detailed information about SANS and data fitting process can be found in reference [Chen et al., 2021].

The tensile deformation of heat-treated AlMg and AlMgScZr alloys was carried out at room temperature $(298 \mathrm{~K})$ using strain rates between $5 \times 10^{-1}-1.0 \times 10^{-6} \mathrm{~s}^{-1}$. The gauge section of tensile specimens with dog-bone shape was $15 \times 3 \times 2 \mathrm{~mm}^{3}$. The dislocation densities of extruded AlMg and AlMgScZr alloys were determined by high resolution X-ray diffraction line profile analysis (XLPA), which were measured by synchrotron radiation X-ray diffraction (SRXRD) conducted at BL14B1 beamline in Shanghai Synchrotron Radiation Facility (SSRF). The average dislocation density was determined from the asymptotic behavior of the second and fourth-order restricted moments [Borb ély and Groma, 2001] of the intensity distribution corresponding to the 200, 220 and 311 diffraction peaks of the samples. the dislocation density in this study is determined by variance method. The asymptotic behavior of the variance in our method does not depend on dislocation arrangement [Kalácska et al., 2017]. This is because the asymptotic behavior is only influenced by the strain field in the vicinity of dislocations and not by the dislocation arrangement (dislocations far away). This is a well-known property of the Fourier transform linking small distances in the real space (close to dislocations) to large distances in the wave vector space (the tails of the diffraction peak). Therefore, the determined total dislocation density by SRXRD is reliable, although the distribution of dislocation is non-uniform in AlMgScZr-623K/3h alloy (seen discussion section). The detailed information about variance method is shown in supplementary materials.

\section{Results and analysis}

\subsection{Quantitative characterization of $\mathrm{Al}_{3}(\mathrm{Sc}, \mathrm{Zr})$ precipitates}

Fig. 1 shows dark-field TEM images of $\mathrm{Al}_{3}(\mathrm{Sc}, \mathrm{Zr})$ precipitates and the corresponding selected area electron diffraction (SAED) patterns for 
AlMgScZr-623K/3h, AlMgScZr-773K/3h and AlMgScZr-813K/24h alloys. The precipitates have a spherical shape and are distributed relatively uniformly in the aluminum matrix (Fig. 1). Fig. 2 shows the curves of scattering intensity $I$ versus scattering vector $q$ captured by SANS and the corresponding raw two-dimensional scattering data for these three kinds of AlMgScZr alloys. The mean radius, volume fraction and precipitate inter-distance obtained from SANS are shown in Table 1. The results in Table 1 reveal that precipitate size increases with increasing aging temperature and mean radius is about 2.5, 10.2 and $22.6 \mathrm{~nm}$ for AlMgScZr-623K/3h, AlMgScZr-773K/3h, AlMgScZr-813K/24h alloys. The corresponding volume fraction of these three samples is about $0.46 \%, 0.42 \%$ and $0.40 \%$, which remains practically unchanged considering the error of the evaluation of about $10 \%$. The results also show that the increase of precipitate size leads to an increase of inter-precipitate distance (Table 1) [Knipling et al., 2010, 2011]. The quantitative information on $\mathrm{Al}_{3}(\mathrm{Sc}, \mathrm{Zr})$ (average radius and volume fraction) obtained by TEM and SANS is close to the previous results for the Al-Sc-Zr systems [Seidman et al., 2002; Fuller et al., 2003; Clouet et al., 2005; Marquis and Seidman, 2005; Deschamps et al., 2007; Knipling et al., 2010; Taendl et al., 2016]. It can be seen from Table 1 that the precipitate radius for $\mathrm{AlMgScZr}-623 \mathrm{~K} / 3 \mathrm{~h}$ alloy is smaller than $3 \mathrm{~nm}$ (the critical radius between shearable and nonshearable precipitates is about 3-4 $\mathrm{nm}$ [Fazeli et al., 2008; Knipling et al., 2010; Lai et al., 2013; Okle et al., 2019; Chen et al., 2021], thus the precipitates in this alloy are defined as shearable precipitates. Analogously, the precipitates in $\mathrm{AlMgScZr}-773 \mathrm{~K} / 3 \mathrm{~h}$ and $\mathrm{AlMgScZr}-813 \mathrm{~K} / 24 \mathrm{~h}$ alloys are defined as nonshearable precipitates. In order to verify that the above definition on precipitates in the three AlMgScZr alloys are reasonable, their strengthening effect are quantified by comparing model prediction and experimental results, as discussed in 4.1 section. The model prediction and experimental results are in good agreement within experimental accuracy, further demonstrating the precipitates in AlMgScZr-623K/3h alloy are shearable as well as in AlMgScZr-773K/3h and AlMgScZr-813K/3h alloys are nonshearable. 

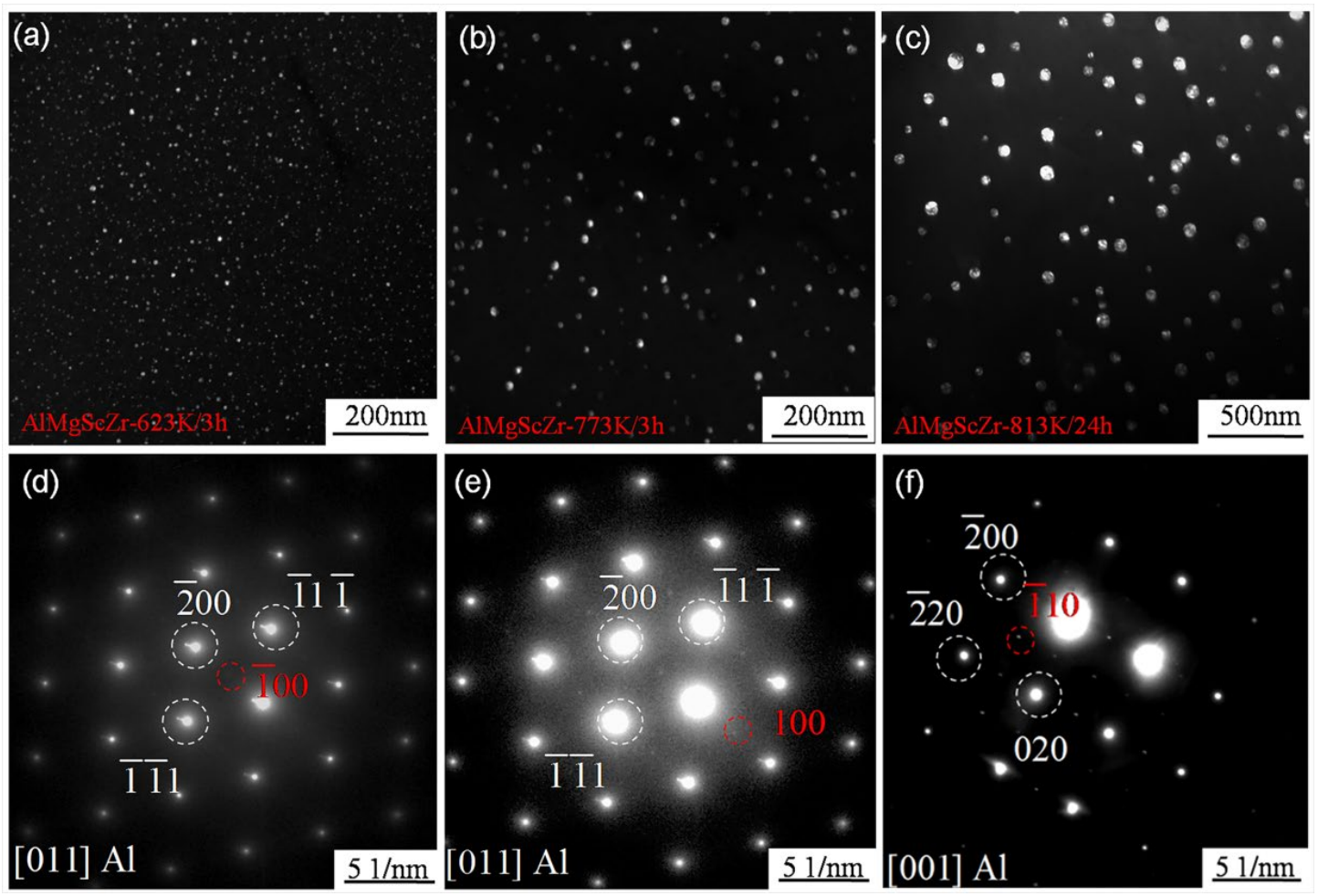

Fig. 1 Characterization on $\mathrm{Al}_{3}(\mathrm{Sc}, \mathrm{Zr})$ precipitates by dark-field TEM. The dark-field TEM images of $\mathrm{Al}_{3}(\mathrm{Sc}, \mathrm{Zr})$ precipitates of (a) AlMgScZr-623K/3h alloy, (b) AlMgScZr-773K/3h alloy and (c) AlMgScZr-813K/24h alloy; (d-f) the corresponding SAED patterns of (a-c). The extracted spots for above dark-field images (a-c) are

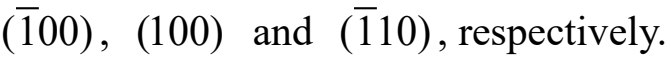
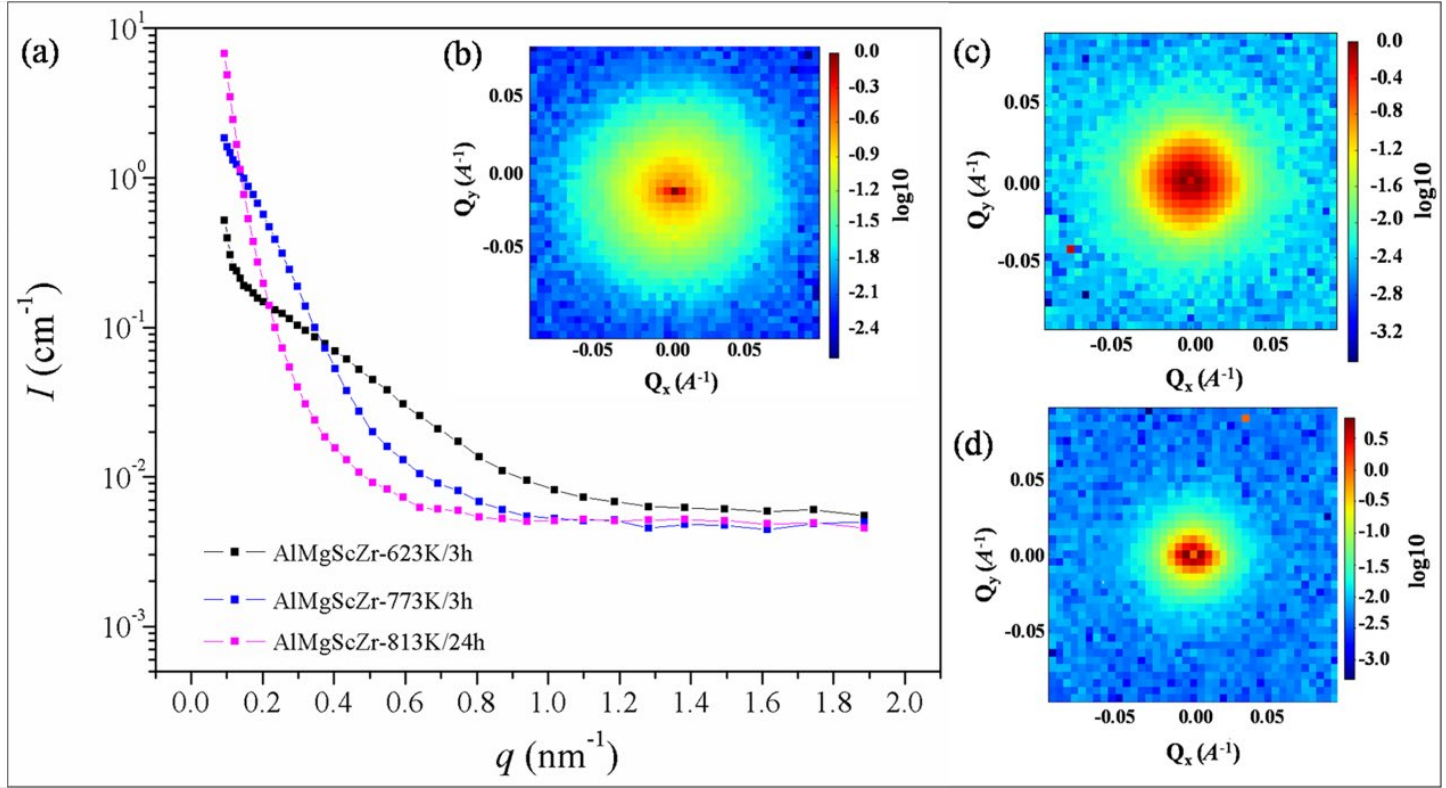

232 Fig. 2 Quantitative characterization on precipitates by SANS. (a) Scattering intensity $I$ versus scattering vector $q$ for AlMgScZr-623K/3h [Chen et al., 2021], AlMgScZr-773K/3h [Chen et al., 2021] and AlMgScZr-813K/24h alloys; (b-d) the corresponding raw two-dimensional scattering data for AlMgScZr-623K/3h, 
237 figure (a).

Table 1 Quantitative information on precipitates provided by SANS and precipitate attribute. The critical precipitate size between shearable and nonshearable precipitates is about 3-4 $\mathrm{nm}$. When the radius of precipitates is smaller than $3 \mathrm{~nm}$, the precipitates are defined shearable precipitates. When the radius of precipitates is higher than $4 \mathrm{~nm}$, the precipitates are defined as nonshearable precipitates.

\begin{tabular}{ccccc}
\hline Samples & $\begin{array}{c}\text { Average } \\
\text { radius }(\mathrm{nm})\end{array}$ & $\begin{array}{c}\text { Volume } \\
\text { fraction }(\%)\end{array}$ & $\begin{array}{c}\text { Inter-distance } \\
(\mathrm{nm})\end{array}$ & $\begin{array}{c}\text { Precipitate } \\
\text { attribute }\end{array}$ \\
\hline $\mathrm{AlMg}$ & - & - & - & without precipitates \\
$\mathrm{AlMgScZr}-623 \mathrm{~K} / 3 \mathrm{~h}$ & $2.5 \pm 0.7$ & $0.46 \pm 0.05$ & 49.4 & shearable precipitates \\
$\mathrm{AlMgScZr}-773 \mathrm{~K} / 3 \mathrm{~h}$ & $10.2 \pm 2.2$ & $0.42 \pm 0.04$ & 211.7 & nonshearable precipitates \\
$\mathrm{AlMgScZr}-813 \mathrm{~K} / 24 \mathrm{~h}$ & $22.6 \pm 4.9$ & $0.40 \pm 0.03$ & 481.5 & nonshearable precipitates \\
\hline
\end{tabular}
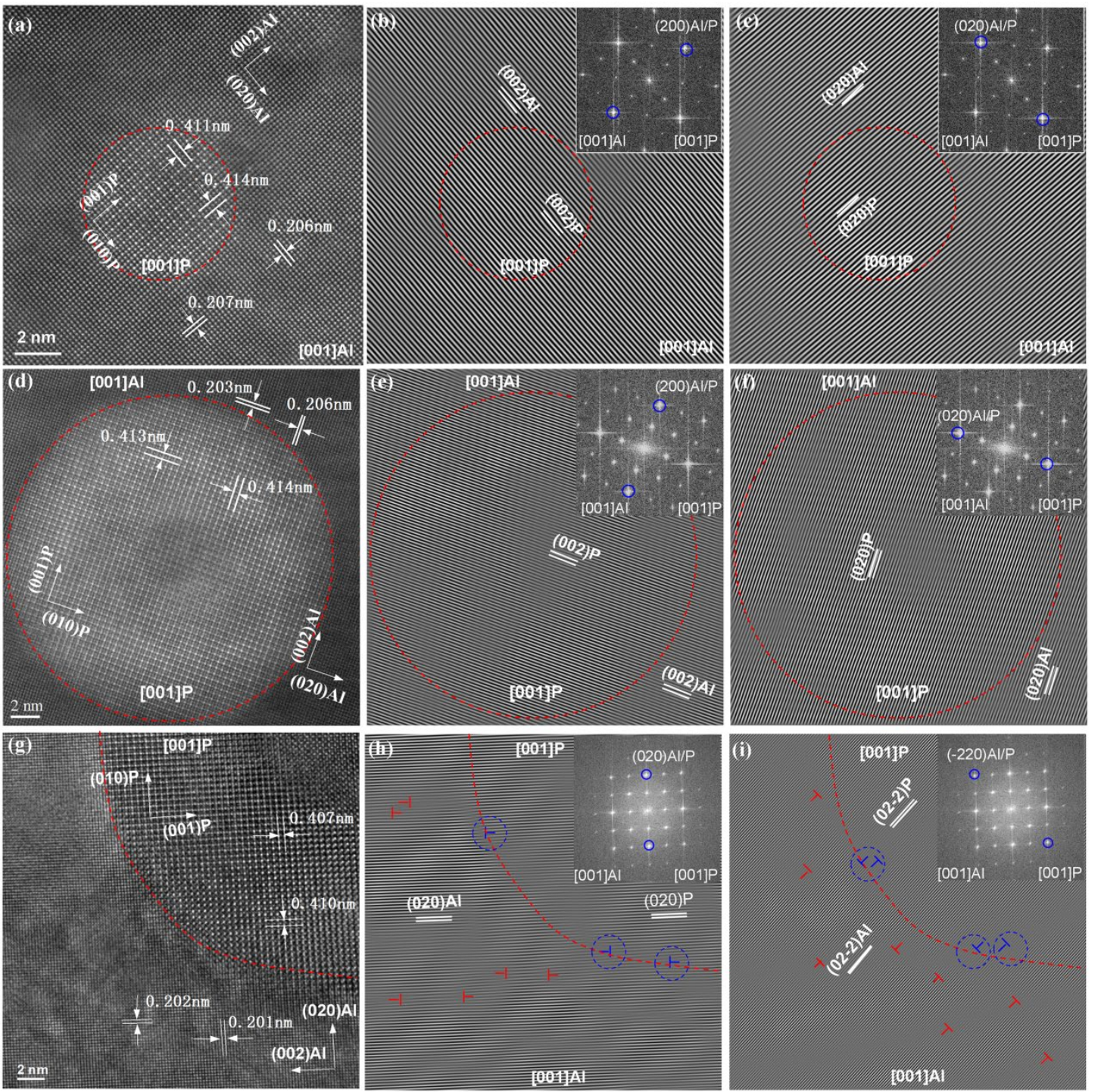
Fig. 3 HRTEM and IFFT images of shearable and nonshearable $\mathrm{Al}_{3}(\mathrm{Sc}, \mathrm{Zr})$ precipitates: (a-c) shearable precipitates (in the AlMgScZr-623K/3h sample); (d-f) nonshearable and coherent precipitates (in the AlMgScZr-773K/3h sample); (g-i) nonshearable and semi-coherent precipitates (in the AlMgScZr-813K/24h sample). (a), (d) and (g) are HRTEM images, (b-c), (e-f) and (h-i) are corresponding IFFT images. The red dashed lines represent the boundary between aluminum matrix and precipitates. The red "T" denotes dislocations in the aluminum matrix, while the blue " $T$ " refers to interfacial dislocations. No interfacial dislocations are observed for AlMgScZr-623K/3h and AlMgScZr-773K/3h samples (coherent precipitates) and lots of interfacial dislocations are observed for AlMgScZr-813K/24h sample (semi-coherent precipitates). The (002)Al, (020)Al, (001)P, (010)P refers to the (002), (020) crystallographic planes of aluminum matrix and (001), (010) crystallographic planes of the precipitates, respectively; [001]P and [001]Al represent the crystal zone axis for the precipitate and matrix, respectively.

Figs. 3(a), (d) and (g) show high resolution TEM (HRTEM) images of shearable $\left(\mathrm{AlMgScZr}-623 \mathrm{~K} / 3 \mathrm{~h}\right.$ alloy) and nonshearable $\mathrm{Al}_{3}(\mathrm{Sc}, \mathrm{Zr})$ precipitates (AlMgScZr-773K/3h and AlMgScZr-813K/24 alloys). Their Inverse Fast Fourier Transform (IFFT) reveals that the $\mathrm{Al} / \mathrm{Al}_{3}(\mathrm{Sc}, \mathrm{Zr})$ interface is free of dislocations for the shearable precipitates (Figs. 3(b-c)) and nonshearable precipitates of AlMgScZr-773K/3h alloy (Figs. 3(e-f)), manifesting that the precipitates are coherent with aluminum matrix. However, lots of interfacial dislocations are observed for the nonshearable precipitates of AlMgScZr-813K/24 alloy (Figs. 3(h-i)) demonstrating that the precipitates are semi-coherent with aluminum matrix. According to previous literature [Iwamura and Miura, 2004], the driving force required for the formation of interfacial dislocations mainly results from the elastic energy caused by the lattice misfit. Hence, the appearance of interfacial dislocations indicates loss of coherency [Marquis and Seidman, 2001]. It has been shown for the case of Al-Sc alloys that precipitates are coherent with the aluminum matrix when their average radius $r_{\text {ave }}<15$ $\mathrm{nm}$, and become semi-coherent when $\mathrm{r}_{\mathrm{ave}}>40 \mathrm{~nm}$ [Iwamura and Miura, 2004]. In the intermediate stage $\left(15<\mathrm{r}_{\mathrm{ave}}<40 \mathrm{~nm}\right)$, there are coexisting coherent and semi-coherent precipitates ${ }^{1}$ [Iwamura and Miura, 2004]. Therefore, in this study, precipitates are found to be coherent completely with matrix for AlMgScZr-623K/3h and $\mathrm{AlMgScZr}-773 \mathrm{~K} / 3 \mathrm{~h}$ alloys, but the coherent and semi-coherent precipitates coexist

\footnotetext{
${ }^{1}$ Note: For AlMgScZr alloy, the additions of $\mathrm{Mg}$ and $\mathrm{Zr}$ elements may increase the critical radius between coherent and semi-coherent precipitate due to $\mathrm{Mg}$ and $\mathrm{Zr}$ elements reducing the lattice mismatch between the matrix and precipitate.
} 


\subsection{Deformation curves of AIMg and AIMgScZr alloys}

284

285

286

287

288

289

290

291

292

293

294

295

296

297

298

299

300

301

302

303

304

305

306

307

308

309

310

Fig. 4 shows the engineering stress strain curves of the AlMg and three kinds of AlMgScZr alloys deformed at different strain rates. For the AlMg alloy, the PLC phenomenon occurs in a large interval of strain rate spanning from $1.0 \times 10^{-1} \mathrm{~s}^{-1}$ to $1.0 \times 10^{-6} \mathrm{~s}^{-1}$ (Fig. 4(a)). The deformation curves of AlMgScZr-623K/3h, AlMgScZr-773K/3h and AlMgScZr-813K/24h alloys are displayed in Figs. 4(b), (c) and (d). The corresponding strain-rate ranges for the occurrence of PLC phenomenon are $1.0 \times 10^{-1}-2.5 \times 10^{-4} \mathrm{~s}^{-1}, 1.0 \times 10^{-1}-1.0 \times 10^{-5} \mathrm{~s}^{-1}$ and $1.0 \times 10^{-1}-1.0 \times 10^{-6} \mathrm{~s}^{-1}$. Fig. 5 shows the magnified figures of serrated flow of $\mathrm{AlMg}$ and three $\mathrm{AlMgScZr}$ alloys. From Fig. 5, the PLC phenomenon is manifested by approximately upward stress steps, followed by a stress plateau when strain rate is higher than $1.0 \times 10^{-2} \mathrm{~s}^{-1}$, which is similar to the previous studies [Böhlke et al., 2009; Duan et al., 2021]. When strain rate is less than $1.0 \times 10^{-2} \mathrm{~s}^{-1}$, the PLC appears like saw-like serrations. Type A, B and $\mathrm{C}$ PLC bands are identified from the stress strain curves, and they appear at high, middle and low strain rates respectively (the mixed type $A+B$ is also observed) both for AlMg and three AlMgScZr alloys. Upward steps, locking serrations and unlocking serrations are visible in magnified regions of the deformation curves (Fig. 5).

Figs. 6(a-d) show the variation of critical strain versus strain rate for AlMg and three AlMgScZr alloys. It can be seen that the relation between the critical strain for the onset of PLC and strain rate is non-monotonic for AlMg and three AlMgScZr alloys. Both the "normal" behavior (the critical strain for the occurrence of PLC increases with the increase in strain rate) and "inverse" behavior (the critical strain for the onset of PLC decreases with the increase in strain rate) are observed for these four materials. Moreover, the type $\mathrm{A}$ and $\mathrm{A}+\mathrm{B} / \mathrm{B}$ bands belongs to normal behavior, while the type $\mathrm{C}$ band belongs to inverse behavior (Figs. 6(a-d)). The critical strain rate for normal and inverse behaviors, the propagation behaviors of PLC bands as well as the serration amplitude all change with the shearable precipitates becoming nonshearable precipitates, which will be analyzed in details in the following section. 

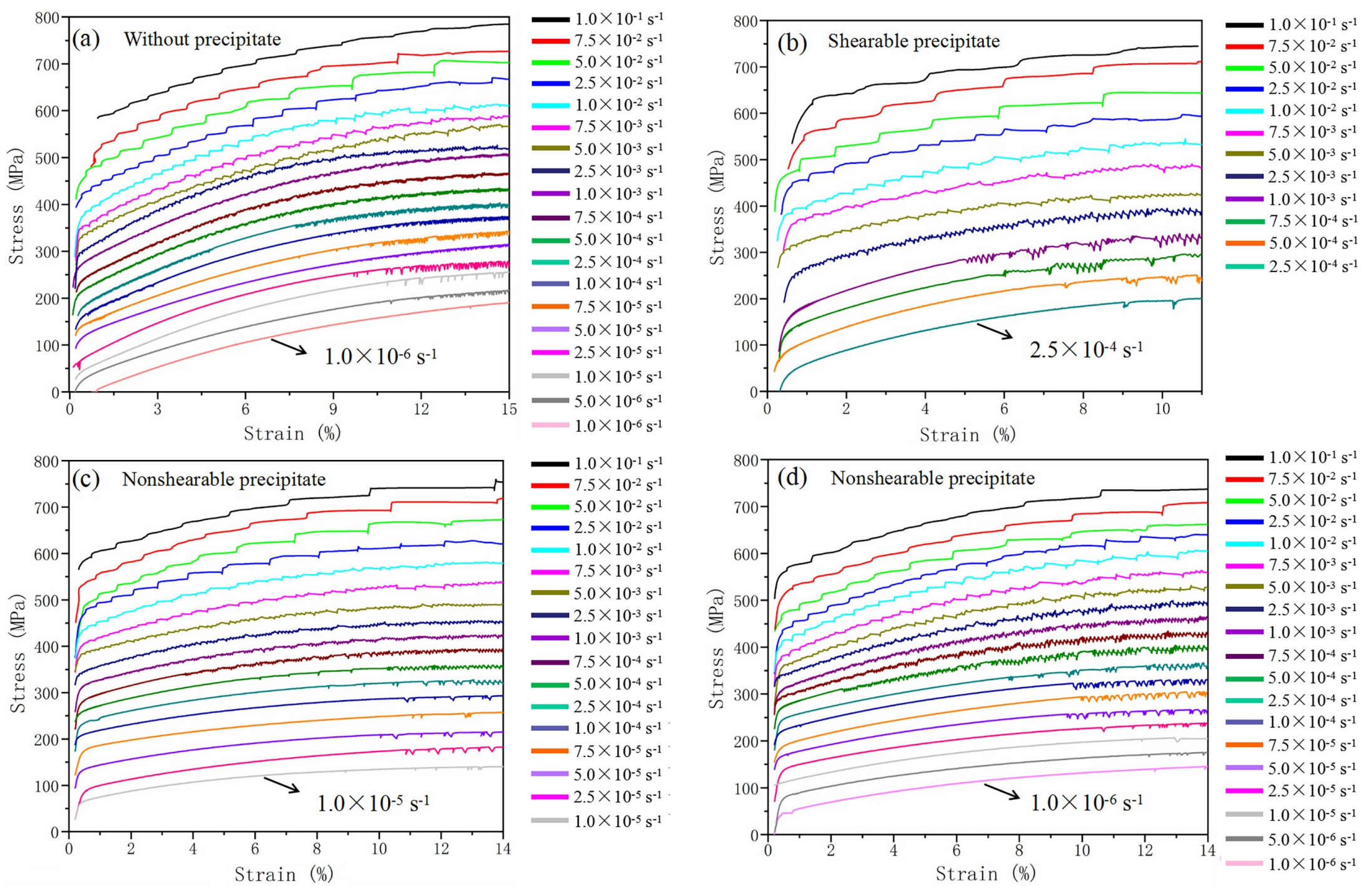
Fig. 4 Engineering stress-strain curves of: (a) AlMg (without precipitates), (b) AlMgScZr-623K/3h (shearable precipitates), (c) AlMgScZr-773K/3h (nonshearable precipitates), (d) AlMgScZr-813K/24h (nonshearable precipitates). For a better view, all curves are vertically displaced by $30-50 \mathrm{MPa}$ and the end of the curves is cut. The upper critical strain rate for the occurrence of PLC is $1.0 \times 10^{-1} \mathrm{~s}^{-1}$ for AlMg and three AlMgScZr alloys. The lower critical strain rates for the occurrence of PLC are $2.5 \times 10^{-4} \mathrm{~s}^{-1}, 1.0 \times 10^{-5} \mathrm{~s}^{-1}$ for AlMgScZr-623K/3h, AlMgScZr-773K/3h alloys. The lower critical strain rate for the occurrence of PLC is smaller than $1.0 \times 10^{-6} \mathrm{~s}^{-1}$ for AlMg and AlMgScZr-813K/24 alloys (Due to the limited tensile condition, we cannot determine the detailed lower values of strain rate for the occurrence of PLC for these two alloys).
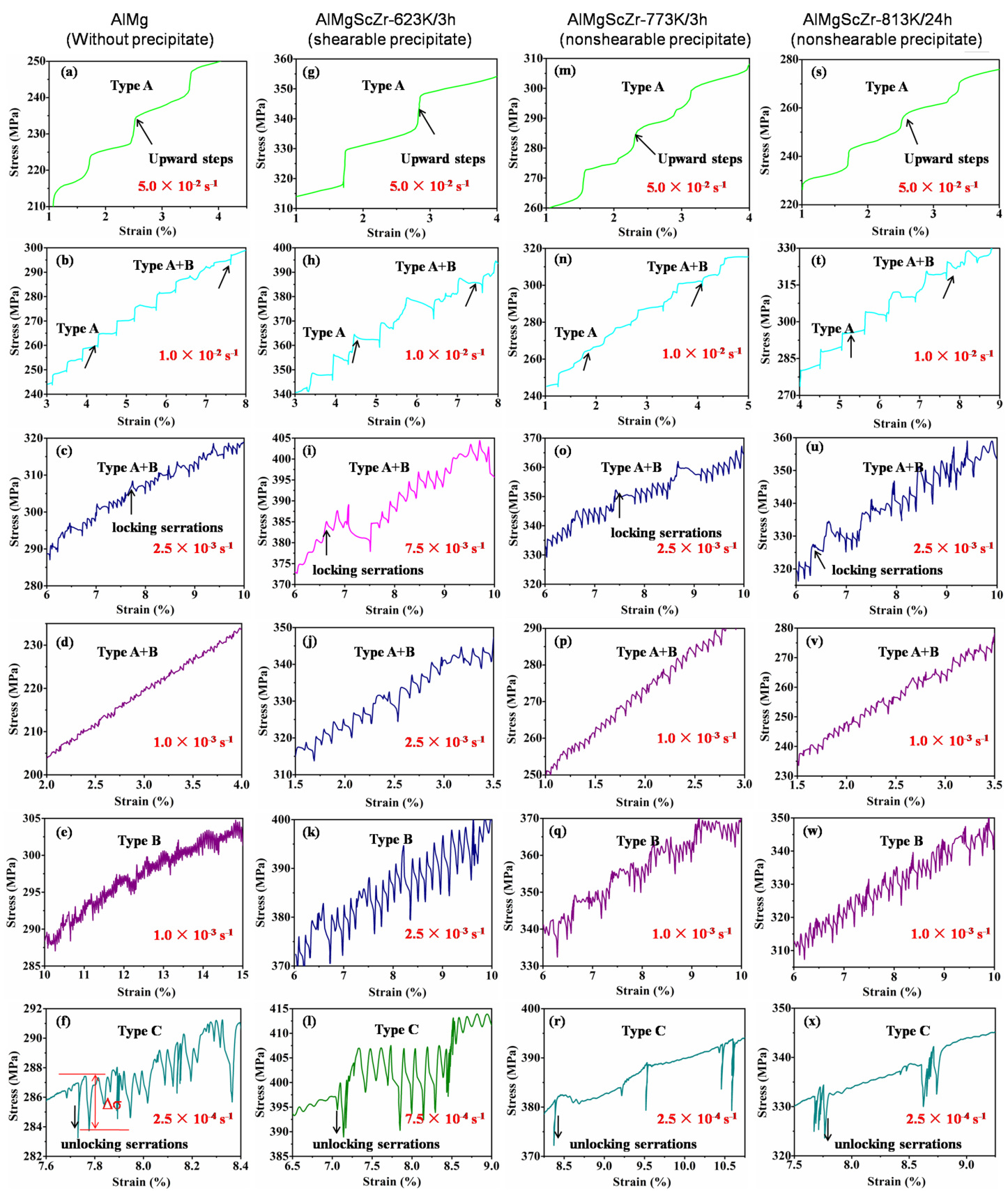
Fig. 5 Magnified figure of jerky flow for the AlMg and three AlMgScZr alloys. (a-f) AlMg alloy; (g-l) AlMgScZr-623K/3h alloy; (m-r) AlMgScZr-773K/3h alloy; (s-x) AlMgScZr-813K/24h alloy. For every column, type A (upward steps) first turns to type $\mathrm{A}+\mathrm{B}$, then to type $\mathrm{B}$ and final to type $\mathrm{C}$ (unlocking serrations) with the decrease of strain rate (from top to bottom). The " $\Delta \sigma$ " in the (f) denotes the serration amplitude, which is described in 3.3.3 section.

\subsection{PLC behavior of AIMg and AIMgScZr alloys}

\subsubsection{Influence of the precipitates on onset strain and strain-rate range of PLC}

The variations of critical strain and critical strain-rate range of PLC in AlMg and three AlMgScZr alloys is illustrated in Fig. 6 and Table 2. For the AlMg alloy, the strain rate dependence of critical strain exhibits normal behavior in the $5.0 \times 10^{-4}-1.0 \times 10^{-1} \mathrm{~s}^{-1}$ range and an inverse behavior in the $1.0 \times 10^{-6}-5.0 \times 10^{-4} \mathrm{~s}^{-1}$ range, as shown in Fig. 6(a) and Table 2. This non-monotonous behavior is also observed for $\mathrm{AlMgScZr}$ alloy with precipitates, but the onset strain and strain-rate ranges of PLC change due to the presence of precipitates (Figs. 6(b-d), (e-1) and Table 2). In the normal behavior, shearable precipitates decrease the onset strain of PLC obviously, but this onset strain increases again with the shearable precipitates being replaced by nonshearable precipitates (Figs. 6(e-h)). However, the precipitates have an opposite effect on the onset strain in the inverse behavior regime. That is the shearable precipitates first increase the onset strain significantly, then the onset strain decreases when shearable precipitates become nonshearable precipitates (Figs. 6(i-1)). 

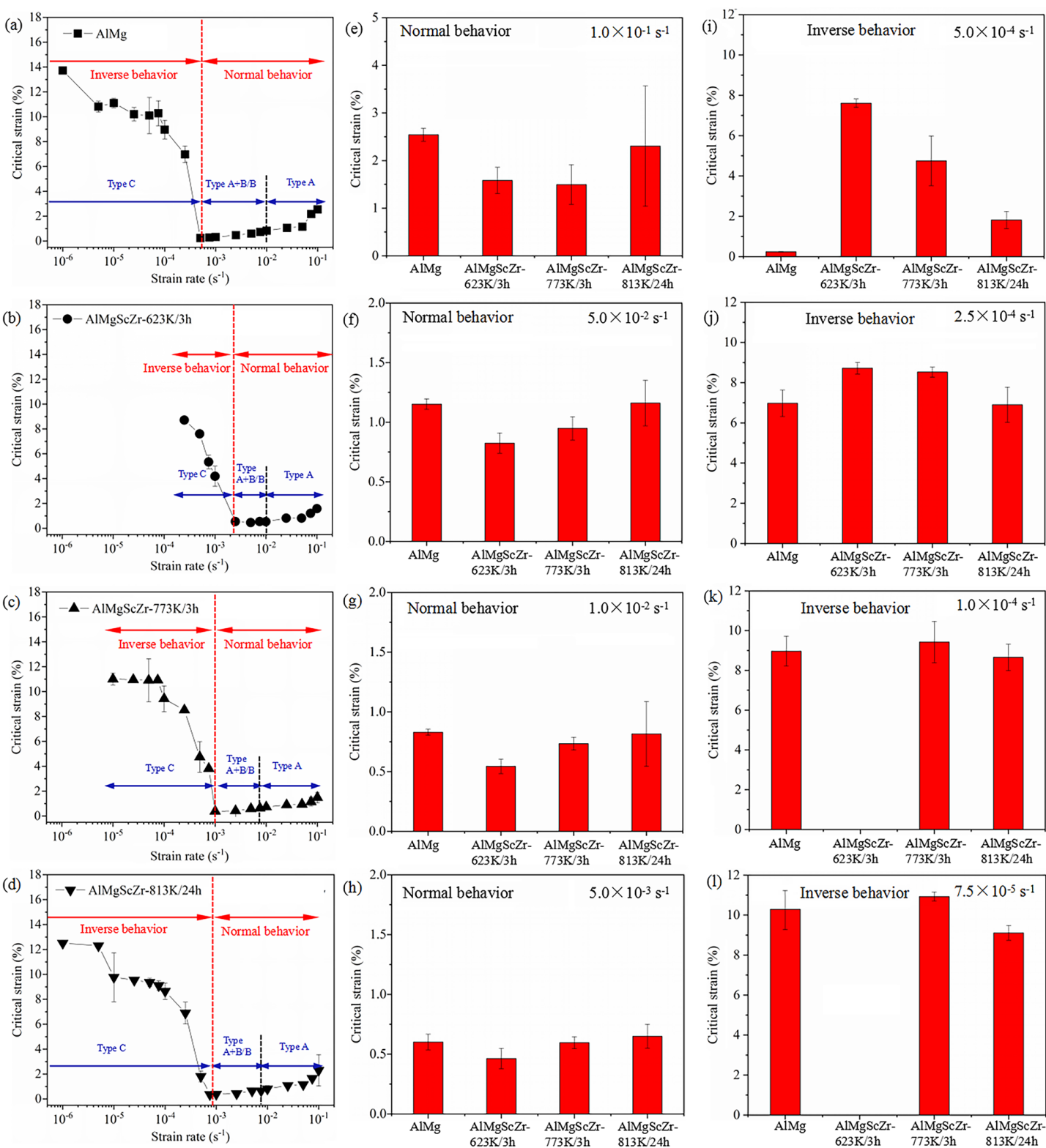

Fig. 6 (a-d) The variation of critical strain versus strain rate for AlMg (without precipitates), AlMgScZr-623K/3h (shearable precipitates), AlMgScZr-773K/3h (nonshearable precipitates) and AlMgScZr-813K/24h (nonshearable precipitates). The black dashed lines are the boundary lines between type A and type $A+B / B$ bands; the red dashed lines are the boundary lines between type $A+B / B$ and type $C$ bands; the red dashed lines also are the boundary lines between normal and inverse behaviors;

(e-h) comparison of critical strain for above alloys at different strain rates for normal behavior:

(e) $1.0 \times 10^{-1} \mathrm{~s}^{-1}$

(f) $5.0 \times 10^{-2} \mathrm{~s}^{-1}$

(g) $1.0 \times 10^{-2} \mathrm{~s}^{-1}$

(h) $5.0 \times 10^{-3} \mathrm{~s}^{-1}$; (i-1) comparison of critical strain for above alloys at different strain rates for inverse behavior: (i) $5.0 \times 10^{-4} \mathrm{~s}^{-1}$,

(j) $2.5 \times 10^{-4} \mathrm{~s}^{-1}$,

(k) $1.0 \times 10^{-4} \mathrm{~s}^{-1}$ (PLC disappears for AlMgScZr-623K/3h alloy),

(l) $7.5 \times 10^{-5} \mathrm{~s}^{-1}($

PLC disappears for AlMgScZr-623K/3h alloy). 
363

Table 2 Strain-rate ranges for normal and inverse behaviors, as well as the critical strain rate between normal and inverse behaviors for AlMg, AlMgScZr-623K/3h, AlMgScZr-773K/3h and AlMgScZr-813K/24h alloys.

\begin{tabular}{cccc}
\hline Samples & $\begin{array}{c}\text { Normal behavior } \\
\text { range }\left(\mathrm{s}^{-1}\right)\end{array}$ & $\begin{array}{c}\text { Inverse behavior } \\
\text { range }\left(\mathrm{s}^{-1}\right)\end{array}$ & $\begin{array}{c}\text { Critical strain } \\
\text { rate }\left(\mathrm{s}^{-1}\right)\end{array}$ \\
\hline $\begin{array}{c}\text { AlMg } \\
\text { (without precipitates) }\end{array}$ & $5.0 \times 10^{-4}-1.0 \times 10^{-1}$ & $1.0 \times 10^{-6}-5.0 \times 10^{-4}$ & $5.0 \times 10^{-4}$ \\
$\begin{array}{c}\text { AlMgScZr-623K/3h } \\
\text { (shearable precipitates) }\end{array}$ & $2.5 \times 10^{-3}-1.0 \times 10^{-1}$ & $2.5 \times 10^{-4}-2.5 \times 10^{-3}$ & $2.5 \times 10^{-3}$ \\
$\begin{array}{c}\text { AlMgScZr-773K/3h } \\
\text { (nonshearable precipitates) }\end{array}$ & $1.0 \times 10^{-3}-1.0 \times 10^{-1}$ & $1.0 \times 10^{-5}-1.0 \times 10^{-3}$ & $1.0 \times 10^{-3}$ \\
$\begin{array}{c}\text { AlMgScZr-813K/24h } \\
\text { (nonshearable precipitates) }\end{array}$ & $7.5 \times 10^{-4}-1.0 \times 10^{-1}$ & $1.0 \times 10^{-6}-7.5 \times 10^{-4}$ & $7.5 \times 10^{-4}$ \\
\hline
\end{tabular}

The critical strain rate for which one observes a transition between normal and inverse behaviors increases evidently when shearable precipitates are introduced. With increasing the precipitate size (from shearable to nonshearable), this critical strain rate decreases continuously and comes back to almost the value observed in the AlMg alloy when the size of nonshearable precipitate is very large (Table 2). On the other hand, by comparing $\mathrm{AlMg}$ and $\mathrm{AlMgScZr}-623 \mathrm{~K} / 3 \mathrm{~h}$ alloys, the strain-rate range reduces from $1.0 \times 10^{-1}-1.0 \times 10^{-6} \mathrm{~s}^{-1}$ to $1.0 \times 10^{-1}-2.5 \times 10^{-4} \mathrm{~s}^{-1}$ with the introduction of shearable precipitates (Table 2). However, the strain-rate range expands when shearable precipitates are replaced by nonshearable precipitates. Finally this strain-rate range becomes similar to that of the AlMg alloy when the nonshearable precipitate size is very large (for AlMgScZr- $813 \mathrm{~K} / 24 \mathrm{~h}$ alloy). It can be seen that the influence of precipitates on strain-rate range is mainly focused on the lower critical strain rate (the lowest strain rate for the appearance of PLC). That is the first increase and then decrease of lower critical strain rate lead to narrowing and expansion of strain-rate range with the introduction of shearable precipitates and subsequent growing into nonshearable precipitates. Therefore, it is concluded that shearable precipitates inhibit the PLC phenomenon at lower strain rate, but this inhibition effect is eliminated gradually when shearable precipitates become nonshearable by coarsening.

\subsubsection{Influence of the precipitates on the propagation behavior of PLC bands}

It is generally accepted that with the decrease in strain rate type A bands turn into 
type B and finally form type C bands [Mogucheva et al., 2016; Zhang et al., 2017]. The corresponding serrations or steps of type A are periodic, and the serrations are usually locking serrations [Jiang et al., 2007; Hu et al., 2012; Zhemchuzhnikova et al., 2015; Zhang et al., 2017] (Figs. 5(a), (g), (m) and (s)). The locking serrations are characterized by an abrupt rise, followed by a drop to the general level of the deformation curve. Type B bands propagate over short distances discontinuously along the gauge direction and then disappear [Jiang et al., 2007; Hu et al., 2012; Zhemchuzhnikova et al., 2015]. The corresponding serrations are locking and oscillating, as shown in Figs. 5(e), (k), (q) and (w). The serrations corresponding to type $\mathrm{C}$ bands are drops in the stress that occur below the general level of the stress strain curve and therefore are considered to be caused by dislocation unlocking [McCormick et al., 1970, 1972b; Jiang et al., 2007; Fu et al., 2012; Zhemchuzhnikova et al., 2015] (Figs. 5(f), (l), (r) and (x)). It should be noted that there is more evident band propagation (smooth intervals) between deep stress drops of type $\mathrm{C}$ for AlMgScZr alloys with precipitates [Zhemchuzhnikova et al., 2017] (Figs. 5(r) and $(\mathrm{x}))$. In this work it is found that type A bands appear in the $1.0 \times 10^{-2}-1.0 \times 10^{-1} \mathrm{~s}^{-1}$ range for AlMg alloy (Figs. 5(a) and 6(a)). It should be noted that in this alloy the first emerging PLC band is of type A at the beginning of deformation, and evolves into type $\mathrm{A}+\mathrm{B}$ bands when the accumulated plastic strain is high, as shown in Fig. 5(b). When strain rate is decreased, mixed type $\mathrm{A}+\mathrm{B}$ bands dominate the deformation curves, as show in Figs. 5(c) and (d). Type B bands can be superimposed on the type $\mathrm{A}+\mathrm{B}$ bands and mainly persist at later stages of deformation [Mogucheva et al., 2016] (Figs. 5(d) and (e)). With further decrease of strain rate, type $\mathrm{C}$ bands appear for the AlMg sample (Fig. 5(f)). Unlocking type C bands do not occur at the beginning of plastic deformation, and they usually occur when plastic strain reaches a certain amount. The introduction of shearable or nonshearable precipitates does not change the habitual sequence of PLC bands, that is, type A bands still transform to type $\mathrm{A}+\mathrm{B} / \mathrm{B}$ band and finally to type $\mathrm{C}$ (Figs. 5(g-1), (m-r) and (s-x)). Precipitation changes only the strain-rate ranges for the appearance of PLC bands, which is depicted in Figs. 6(a-d). It can be seen from Fig. 6(a-d) that the type B bands of AlMg sample (in $5.0 \times 10^{-4}-2.5 \times 10^{-3} \mathrm{~s}^{-1}$ strain-rate range) turn to type $\mathrm{C}$ band when shearable precipitates are introduced, and the type $\mathrm{B}$ bands of $\mathrm{AlMg}$ sample (in $2.5 \times 10^{-3}-1.0 \times 10^{-2} \mathrm{~s}^{-1}$ strain-rate range) remain. It is demonstrated that the shearable precipitates increase the lower strain rate for the appearance of type $\mathrm{C}$ band. With 
shearable precipitates being replaced by nonshearable precipitates, the lower strain rate for the occurrence of type $\mathrm{C}$ band decreases, gradually approaching to that of the $\mathrm{AlMg}$ alloy when precipitate size is very large (for AlMgScZr-813K/24h alloy).

\subsubsection{Influence of the precipitates on serration amplitude}

The serration amplitude is defined as the height of stress drop, corresponding to the vertical distance between a given local maximum and the latter local minimum on the deformation curve [Pink and Grinberg, 1981; Klose et al., 2004; Zhang et al., 2017], as shown in Fig. 5(f). Fig. 7 shows the variation of the serration amplitude versus strain at normal behavior (at higher strain rate). It is found that the serration amplitude largely increases in case of shearable precipitates and decreases with shearable precipitates becoming nonshearable precipitates (Fig. 7). As the strain range for the appearance PLC is narrow for both $\mathrm{AlMg}$ and three AlMgScZr alloys (especially for AlMgScZr-623K/3h, Figs. 4 and 6) in inverse behavior, we do not establish the dependence of serration amplitude versus strain like Fig. 7. We only compare the serration amplitudes of four alloys at a fixed strain, as shown in Fig. 8. It can be seen that the serration amplitude increases with the presence of shearable precipitates, while it decreases when shearable precipitates become nonshearable precipitates. The variation of serration amplitude with the presence of shearable precipitates and subsequent growing into nonshearable at inverse behavior is similar to that at normal behavior.

No matter for normal behavior or inverse behavior, the magnitude of the serration amplitude manifests a measure for the strength of solutes locking the dislocations [Zhang et al., 2017]. Longer dislocation waiting times are associated with lower nominal strain rates, which allow for more solute diffusion [McCormick, 1972a; Zhang et al., 2017]. Therefore, the waiting time of mobile dislocations influences the serration amplitude. Concerning the above mechanism, it is reasonable to link the different precipitate-dislocation interaction mechanisms to the serration amplitude, which will be discussed in the following. 

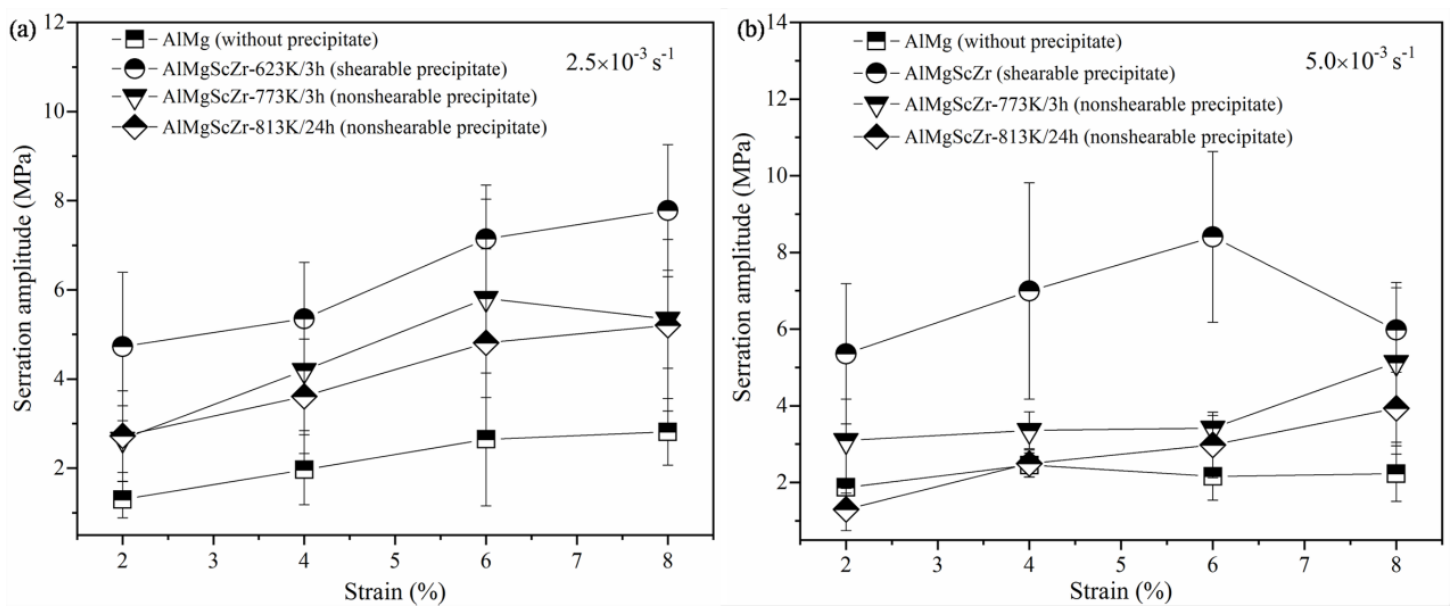

Fig. 7 Serration amplitude in AlMg, AlMgScZr-623K/3h, AlMgScZr-773K/3h and AlMgScZr-813K/24 alloys versus tensile strain at normal behavior (at higher strain rate): (a) $2.5 \times 10^{-3} \mathrm{~s}^{-1}$; (b) $5.0 \times 10^{-3} \mathrm{~s}^{-1}$. The serrations being analyzed are of type $\mathrm{A}+\mathrm{B}$ serration.
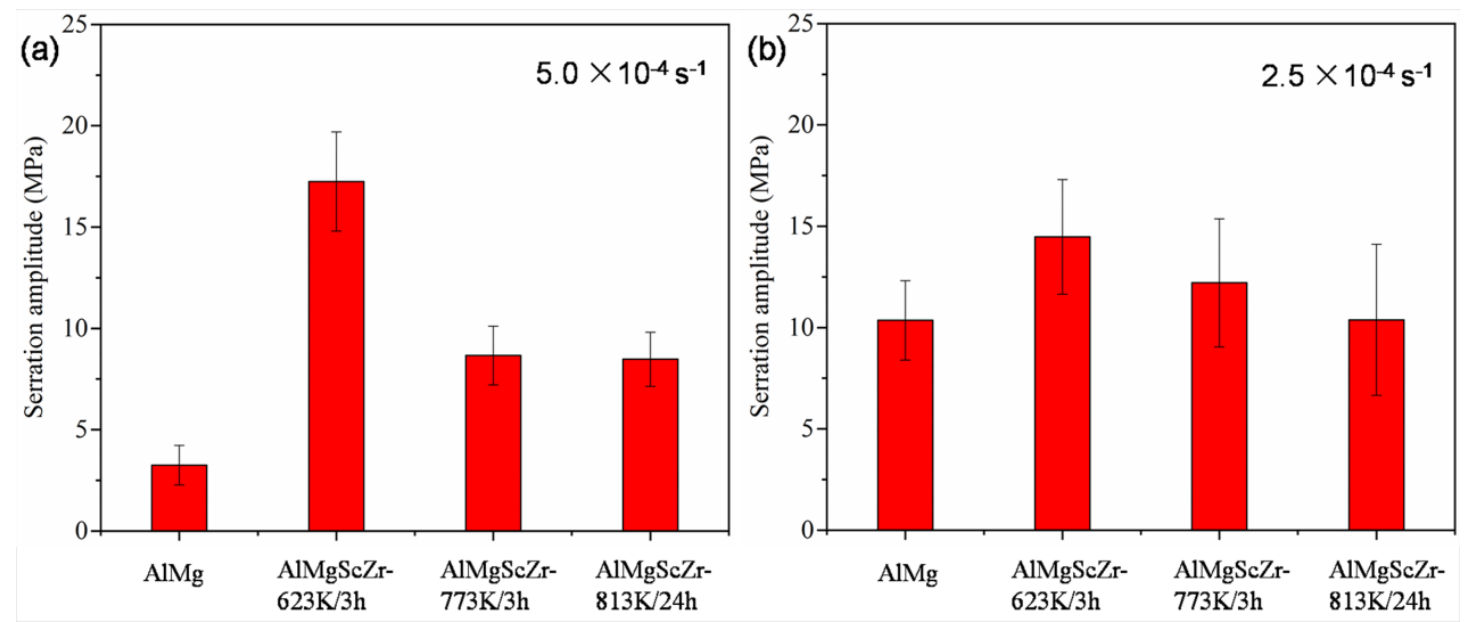

Fig. 8 Serration amplitude in AlMg, AlMgScZr-623K/3h, AlMgScZr-773K/3h and AlMgScZr-813K/24 alloys at same strain (10\%) in inverse behavior: (a) $5.0 \times 10^{-4} \mathrm{~s}^{-1}$, (b) $2.5 \times 10^{-4} \mathrm{~s}^{-1}$. The serrations being analyzed are of type $\mathrm{C}$ serration.

\section{Discussion}

\subsection{Strengthening effect induced by $\mathrm{Al}_{3}(\mathrm{Sc}, \mathrm{Zr})$ precipitates}

It has been reported that the interaction between dislocation and precipitate changes from the shearing mechanism to the Oworan bypassing mechanism with the increase of precipitate size [Ardell, 1985; Gladman, 1999; Knipling et al., 2010; Ma et al., 2014; Ming et al., 2018]. When precipitate size is small, the dislocations can shear the precipitate, thus the dominant strengthening mechanism is the shearing mechanism. In general, the shearing mechanisms mainly include modulus strengthening, coherent 
strengthening and order strengthening [Ardell, 1985; Knipling et al., 2010; Ma et al., 2014].

Firstly, the modulus strengthening, $\sigma_{\text {mod }}$, due to the difference of shear modulus between precipitate and aluminum matrix, is given by [Ardell et al., 1985; Knipling et al., 2010; Ma et al., 2014; Luca et al., 2019]:

$$
\sigma_{\text {mod }}=M \cdot 0.0055(\Delta G)^{3 / 2}(\phi / T)^{1 / 2} \cdot b(R / b)^{3 m / 2-1}
$$

where $M$ is Taylor factor, and $M=3.06$ for face-centered cubic (FCC) polycrystal materials; $\Delta G$ is difference on shear modulus between precipitates $G_{\mathrm{p}}\left(G_{\mathrm{p}}=78 \mathrm{GPa}\right.$ for $\mathrm{Al}_{3} \mathrm{Sc}$ precipitate) and aluminium matrix $G_{\mathrm{m}}\left(G_{\mathrm{m}}=26.2 \mathrm{GPa}\right.$ for aluminium matrix $)$, thus one has $\Delta G=41.8 \mathrm{GPa}$ in this study; $\phi$ and $R$ are the volume fraction and average radius of precipitates, which can be seen in Table $1 ; b$ is the Burgers vector, and $b=0.286 \mathrm{~nm}$ for aluminum; $T$ is the line tension of dislocation, and $T=0.5 G b^{2}=$ $1.072 \times 10^{-9} \mathrm{~N} ; m$ is a constant, and $m=0.85$.

Secondly, the coherent strengthening, $\sigma_{\text {coh }}$, due to the elastic strain field interactions between coherent precipitates and dislocations, is given by [Ardell et al., 1985; Knipling et al., 2010; Ma et al., 2014; Luca et al., 2019]:

$$
\sigma_{\text {coh }}=M \cdot \chi\left(\xi G_{m}\right)^{3 / 2} \cdot(R \phi b / T)^{1 / 2}
$$

where $\chi$ is a constant, and $\chi=2.6$; $\xi$ is a misfit parameter, which describes the misfit degree between precipitate and dislocation, and $\xi=0.0179$.

Thirdly, the order strengthening, $\sigma_{\text {ord }}$, resulting from the formation of antiphase boundaries (APBs), occurs when the mobile dislocations shear the ordered precipitate, which is shown as [Ardell et al., 1985; Knipling et al., 2010; Ma et al., 2014; Luca et al., 2019]:

$$
\sigma_{\text {ord }}=M \cdot\left(0.81 \eta_{A P B S} / 2 b\right) \cdot(3 \pi \phi / 8)^{1 / 2}
$$

where $\eta_{A P B S}$ is the average APBs energy for (111) plane, and $\eta_{A P B S}=0.5 \mathrm{~J} \mathrm{~m}^{-2}$ for $\mathrm{Al}_{3} \mathrm{Sc}$ precipitate.

When precipitate size is large, the dislocations cannot shear the precipitate, the dominant strengthening mechanism is Orowan strengthening. The Orowan strengthening $\sigma_{\text {oro }}$ can be expressed as [Knipling et al., 2010; Ma et al., 2014; Luca et al., 2019]:

$$
\sigma_{\text {oro }}=0.4 M G b \ln (2 \bar{R} / b) / \pi L_{p} \sqrt{1-v}
$$


where $\bar{R}$ is the average planar radius, and $\bar{R}=0.25 R ; L_{p}$ is the average inter-distance of precipitates, and $L_{p}=R \sqrt{(2 \pi / 3 \phi)-\pi / 2}$. The values of $L_{p}$ for three AlMgScZr alloys are shown in Table 1.

For Al-Sc-Zr based alloy systems, the dominant precipitation strengthening mechanism depends on the average radius of precipitate [Knipling et al., 2010; Lai et al., 2013; Luca et al., 2019; Okle et al., 2019]. For smaller precipitates $\left(R<R_{1}\right)$ modulus plus coherency effects are dominant, while above $R_{1}$ and below $R_{2}$, order strengthening becomes important. If the precipitate size overcomes a certain limit ( $R>R_{2}$ ), order strengthening is replaced by the strengthening effect associated with the Orowan bypassing mechanism. The increase in strength as a function of precipitate size can thus be summarized as follows:

$$
\Delta \sigma= \begin{cases}\sqrt{\sigma_{\text {mod }}^{2}+\sigma_{\text {coh }}^{2}}, & R<R_{1} \\ \sigma_{\text {ord }}, & R_{1}<R<R_{2} . \\ \sigma_{\text {oro }}, & R>R_{2}\end{cases}
$$

Here $R_{1}$ is the critical radius between combined modulus-coherent strengthening and order strengthening; $R_{2}$ is the critical radius between order strengthening (or shearing mechanism) and Orowan strengthening. According to previous studies [Fazeli et al., 2008; Knipling et al., 2010; Okle et al., 2019; Chen et al., 2021], $\mathrm{R}_{1} \approx 1.2 \mathrm{~nm}$ and $\mathrm{R}_{2} \approx 3-4 \mathrm{~nm}$ for Al-Sc-Zr alloy [Fazeli et al., 2008; Knipling et al., 2010, 2011; Lai et al., 2013; Luca et al., 2019; Okle et al., 2019]. Besides, we calculate the critical radius $R_{c}$, for the transition between the shearing and bypassing mechanisms, which according to reference [Bréchet and Louchet, 1990]:

$$
R_{c}=\sqrt{3 / 2}(\Gamma / \gamma)\left[1+1.53(\phi / \pi)^{1 / 2}\right]
$$

where $\Gamma$ is the line tension of dislocation; $\gamma$ is the interface energy. It can be seen that $R_{c}$ not only depends on the alloy system $(\Gamma)$ and precipitate type $(\gamma)$, but also depends on the volume fraction of precipitates. Generally, the value of $\phi$ is much smaller than $\pi$ for Al-Sc or Al-Sc-Zr alloys, thus $R_{c}$ mainly depends on $\Gamma$ and $\gamma$. According to Eq. (6), the calculated $R_{c}=2.8 \mathrm{~nm}$ for $\mathrm{Al}_{3} \mathrm{Sc}$ precipitate (for (111) plane, $\gamma=0.5 \mathrm{~J} \mathrm{~m}^{-2}$ [Knipling et al., 2010]) and $3.1 \mathrm{~nm}$ (for the (111) plane, 
$\gamma=0.445 \mathrm{~J} \mathrm{~m}^{-2}$ [Lefebvre et al., 2014]) for $\mathrm{Al}_{3} \mathrm{Zr}$ precipitate. The calculated values are close to those given by references [Fazeli et al., 2008; Knipling et al., 2010; Lai et al., 2013; Okle et al., 2019], further supporting that the $3 \mathrm{~nm}$ is a reasonable value for the critical size between shearing and bypassing mechanisms for Al-Sc-Zr alloy.

According to Eq. (5), the dominant strengthening mechanism in $\mathrm{AlMgScZr}-623 \mathrm{~K} / 3 \mathrm{~h}$ alloy is order strengthening, since the average size is $2.5 \mathrm{~nm}$ and belongs to $\left(R_{1}, R_{2}\right)$ range. Similarly, the dominant strengthening mechanisms in $\mathrm{AlMgScZr}-773 \mathrm{~K} / 3 \mathrm{~h}$ and $\mathrm{AlMgScZr}-813 \mathrm{~K} / 24 \mathrm{~h}$ alloys are Orowan bypassing mechanisms, since their average radius sizes $(10.2$ and $22.6 \mathrm{~nm})$ are larger than $R_{2}$.

In order to verify that the determined strengthening mechanisms are reliable, the results between experiments and strengthening model prediction are compared. Table 3 shows the yield stress of AlMg and three AlMgScZr alloys at different strain rates. The estimated yield stress increment as a function of precipitate size is shown in Fig. 9 together with the experimental values obtained in this work. For AlMgScZr-623K/3h sample (Fig. 9(a)), the predicted values by combined modulus-coherent strengthening, order strengthening and Orowan strengthening are 210, 159, $190 \mathrm{MPa}$, respectively. The experimental value is about $140 \mathrm{MPa}$, which is close to the prediction of order strengthening. Thus, it is further verify that the dominant strengthening mechanism in AlMgScZr-623K/3h alloy is the order strengthening. The experimental value is slightly smaller than the prediction of order strengthening, which is due to the overestimated APBs energy of $\mathrm{Al}_{3} \mathrm{Sc}$ precipitate. Our results are similar to that of Knipling et al. who reported that the calculated value is higher than the experimental one due to the slightly overestimated APBs energy [Knipling et al., 2010]. For AlMgScZr-773K/3h and AlMgScZr-813K/24h samples (Figs. 9(b) and (c)), the predicted values by combined modulus-coherent strengthening and order strengthening are much higher than experimental values. While the predicted values by Orowan strengthening are very close to the experimental values. Thus, it is further proved that the dominant strengthening mechanisms are Orowan strengthening for these two samples.

In general, it can be confirmed that the interaction mechanisms between precipitate and dislocation for three AlMgScZr alloys, providing the theoretical basis for analyzing the influence of precipitates on dislocation motion, distribution and multiplication, and finally providing a good theoretical support for studying the 
influence of precipitates on the PLC behavior.

Table 3 Experimentally determined yield stress of $\operatorname{AlMg}\left(\sigma_{\mathrm{s} 1}\right), \operatorname{AlMgScZr}-623 \mathrm{~K} / 3 \mathrm{~h}\left(\sigma_{\mathrm{s} 2}\right)$, AlMgScZr-773K/3h $\left(\sigma_{\mathrm{s} 3}\right)$ and AlMgScZr-813K/24h $\left(\sigma_{\mathrm{s} 4}\right)$ alloys.

\begin{tabular}{cccccc}
\hline Strain rate $\left(\mathbf{s}^{-\mathbf{1}}\right)$ & $\mathbf{1 \times \mathbf { 1 0 } ^ { - \mathbf { 2 } }}$ & $\mathbf{5 \times 1 \mathbf { 1 0 } ^ { - \mathbf { 3 } }}$ & $\mathbf{1 \times \mathbf { 1 0 } ^ { - 3 }}$ & $\mathbf{5 \times 1 0 ^ { - 4 }}$ & $\mathbf{1 \times \mathbf { 1 0 } ^ { - 4 }}$ \\
\hline$\sigma_{\mathrm{s} 1}(\mathrm{MPa})$ & $168.4 \pm 4.8$ & $162.3 \pm 1.9$ & $170.7 \pm 4.9$ & $173.6 \pm 2.9$ & $173.2 \pm 4.0$ \\
$\sigma_{\mathrm{s} 2}(\mathrm{MPa})$ & $301.0 \pm 4.0$ & $302.0 \pm 5.9$ & $305.4 \pm 2.5$ & $311.6 \pm 16.4$ & $306.0 \pm 4.2$ \\
$\sigma_{\mathrm{s} 3}(\mathrm{MPa})$ & $233.8 \pm 5.5$ & $235.8 \pm 5.5$ & $242.6 \pm 19.1$ & $237.2 \pm 2.1$ & $235.6 \pm 5.1$ \\
$\sigma_{\mathrm{s} 4}(\mathrm{MPa})$ & $216.6 \pm 5.5$ & $212.9 \pm 10.1$ & $214.8 \pm 6.1$ & $221.7 \pm 4.9$ & $216.2 \pm 2.4$ \\
\hline
\end{tabular}

(a)

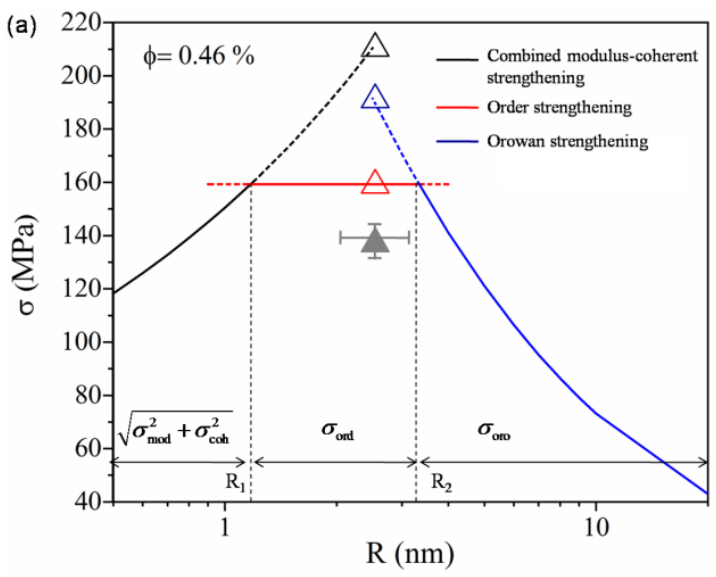

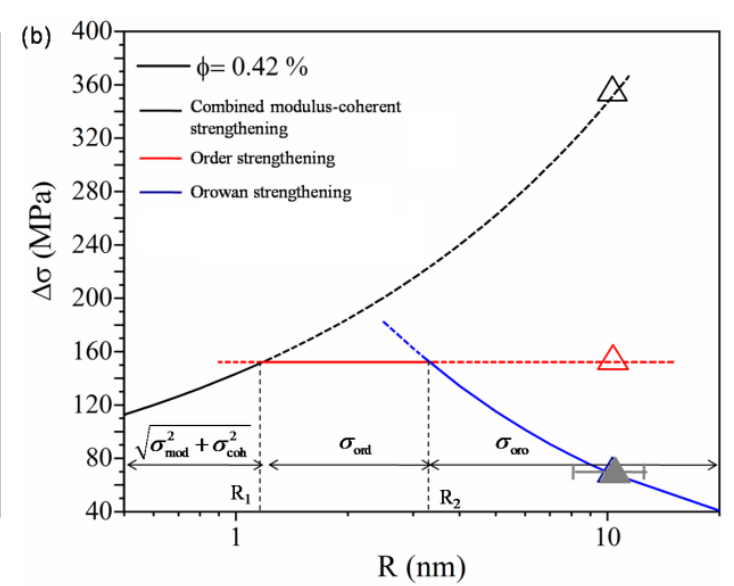

(b)

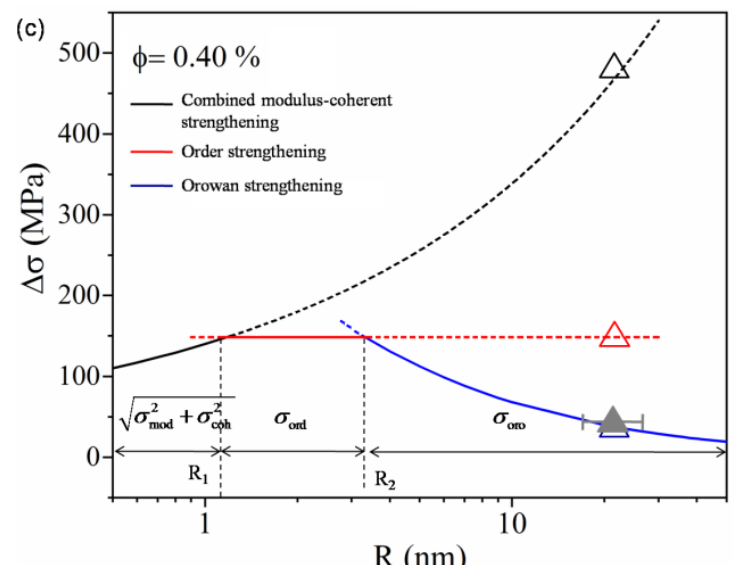

565

566

567

568

569

570

Fig. 9 Yield stress increment versus mean precipitate radius for (a) AlMgScZr-623K/3h [Chen et al., 2021], (b) AlMgScZr-773K/3h [Chen et al., 2021] and (c) AlMgScZr-813K/24h. The full curves in (a-c) represent calculated predictions of minimum of $\sqrt{\sigma_{\text {mod }}^{2}+\sigma_{\text {coh }}^{2}}, \sigma_{\text {ord }}$, and $\sigma_{\text {oro }}$. That is, it is taken the minimum value of $\sqrt{\sigma_{\text {mod }}^{2}+\sigma_{\text {coh }}^{2}}, \sigma_{\text {ord }}$, and $\sigma_{\text {oro }}$ as the true strengthening increment according to 
the previous study [Knipling et al., 2010]. The solid symbols in (a-c) represent the yield stress increment obtained from tensile tests. The empty symbols in (a-c) refer to predictions for a certain precipitate radius and volume fraction obtained from SANS: (a) $R=2.5 \mathrm{~nm}, \phi=0.46 \%$; (b) $R=10.2 \mathrm{~nm}, \phi=0.42 \%$; (c) $R=22.6 \mathrm{~nm}, \phi=0.40 \%$.

\subsection{Effects of precipitates on dislocation motion, distribution and multiplication}

The strengthening induced by $\mathrm{Al}_{3}(\mathrm{Sc}, \mathrm{Zr})$ precipitates is quantified in the 4.1 section, proving the different precipitate-dislocation mechanisms for different AlMgScZr samples in this study. According to Fig. 9, order strengthening dominates in the AlMgScZr-623K/3h alloy demonstrating that matrix dislocations shear ordered precipitates and create antiphase boundaries (APBs) on the slip plane in the precipitate. Moreover, Fig. 10 shows the precipitate structure of AlMgScZr-623K/3h alloy after a certain degree of tensile strain (5\%). It can be evidently seen that the precipitates are sheared by dislocations in Fig. 10. The APBs energy per unit area can also be interpreted as the force per unit length opposing the dislocation motion when it penetrates the precipitate. During this process, dislocations travel in pairs (so called "superdislocations"), the second dislocation removes the APBs left by the first one [Ardell, 1985]. Recent work of Lefebvre et al. [Lefebvre et al., 2014] revealed that the $\mathrm{APBs}$ in $\mathrm{Al}_{3} \mathrm{Zr}$ can be the consequence of successive shearing of [1110]/2 Burgers vector dislocations gliding on distinct (111) planes. Under this circumstance, when the ahead dislocations pass through the precipitate, the subsequent dislocations are prone to move along the specific shear planes owing to its reduced motion resistance, leading to the formation of slip bands (Fig. 11). It can be seen from Fig. 11 that the slip bands with high density of dislocations form. It is clearly shown that lots of dislocation lines parallel with each other in the slip bands, indicating that dislocation pile-ups in slip bands are the results of dislocation motion along above specific shear planes. Although it is difficult to observe the $\mathrm{Al}_{3}(\mathrm{Sc}, \mathrm{Zr})$ precipitate inside the slip bands, the corresponding SAED of slip bands can confirm the existence of precipitates (Fig. 11(g)). Moreover, we observe the slip bands with relatively low dislocation density with the aid of scanning transmission electron microscope (STEM), as shown in Fig. A1 (supplementary materials). It observes lots of precipitates inside slip bands in the high magnification STEM images. Previous studies also have shown that the slip bands form due to dislocations shearing precipitates [Poole et al., 2005; Xiao et al., 2005; Sharma et al., 2009; Tayon et al., 
2019; Jaladurgam et al., 2020; Chen et al., 2021], which makes the distribution of dislocations extremely non-uniform. Due to the formation of slip bands, the strain is distributed in a limited volume for the AlMgScZr-623K/3h alloy with shearable precipitates. As a result, the local strain rate and the resultant local strain in the AlMgScZr-623K/3h alloy is higher than the macroscopic equivalent strain. Therefore, although single shearable precipitate cannot accumulate dislocations directly, the shearing process of such precipitates can store a large number of dislocations by the formation of slip bands.

With the shearable precipitates becoming nonshearable precipitates, the dislocation shearing mechanism is replaced by dislocation bypassing mechanism (for AlMgScZr-773K/3h and AlMgScZr-813K/24h samples). This process leaves Orowan loops around the nonshearable precipitates. The dislocations are distributed relative homogeneously during tensile deformation, which is different from that of AlMgScZr-623K/3h alloy with shearable precipitates, as shown in Figs. 12(b) and (c). It should be noted that the dislocations are also distributed uniformly for the $\mathrm{AlMg}$ sample without precipitates (Fig. 12(a)). Our results are similar to Poole et al. who reported that the shearable and nonshearable precipitates had distinct effects on dislocation distribution through different precipitate-dislocation interactions [Poole et al., 2005].

In order to quantitatively evaluate the dislocation density caused by precipitates, the dislocation densities of $\mathrm{AlMg}, \mathrm{AlMgScZr}-623 \mathrm{~K} / 3 \mathrm{~h}, \mathrm{AlMgScZr}-773 \mathrm{~K} / 3 \mathrm{~h}$ and AlMgScZr-813K/24h were evaluated by XLPA (the detailed evaluation procedure can be found in reference [Borbély and Groma, 2001]). The corresponding (200) peak profiles (as an example) and variations of dislocation densities versus tensile strain are shown in Fig. 13. The dislocation density of the AlMgScZr-623K/3h sample is larger by one order of magnitude compared with that of the AlMg alloy. Dislocation density decreases when shearable precipitates become nonshearable precipitates. The results are in very good agreement with the TEM images (Figs. 11 and 12). It should be noted that the AlMgScZr-623K/3h alloy has the highest dislocation density in all studied alloys, which is mainly due to its higher initial dislocation density retained during hot extrusion. Although the increment on dislocation density in 
AlMgScZr-623K/3h alloy at the beginning stage of tensile deformation is higher than the others, the differences on dislocation density increment caused by tensile deformation for these four samples are relatively small. The AlMgScZr-623K/3h alloy with shearable precipitates has a higher dislocation density storage after hot extrusion deformation, which is mainly due to the fact that the shearable precipitates have stronger pinning effect on dislocations [Humphreys and Hatherly, 2004; Fazeli et al., 2008]. Thus, more dislocations can be retained during hot extrusion. The dislocations in $\mathrm{AlMg}$ alloy without precipitates cannot be arrested and pinned effectively by precipitates, thus the AlMg alloy has the lowest dislocation density storage after hot extrusion. Compared with AlMg alloy, the AlMgScZr-773K/3h and AlMgScZr-813K/24 alloys have a higher density of dislocation storage due to pinning effect by the nonshearable precipitates, but their stored dislocation densities are smaller than that of AlMgScZr-623K/3h alloy, for their pinning effect on dislocations is weaker than that of shearable precipitates [Fazeli et al., 2008].
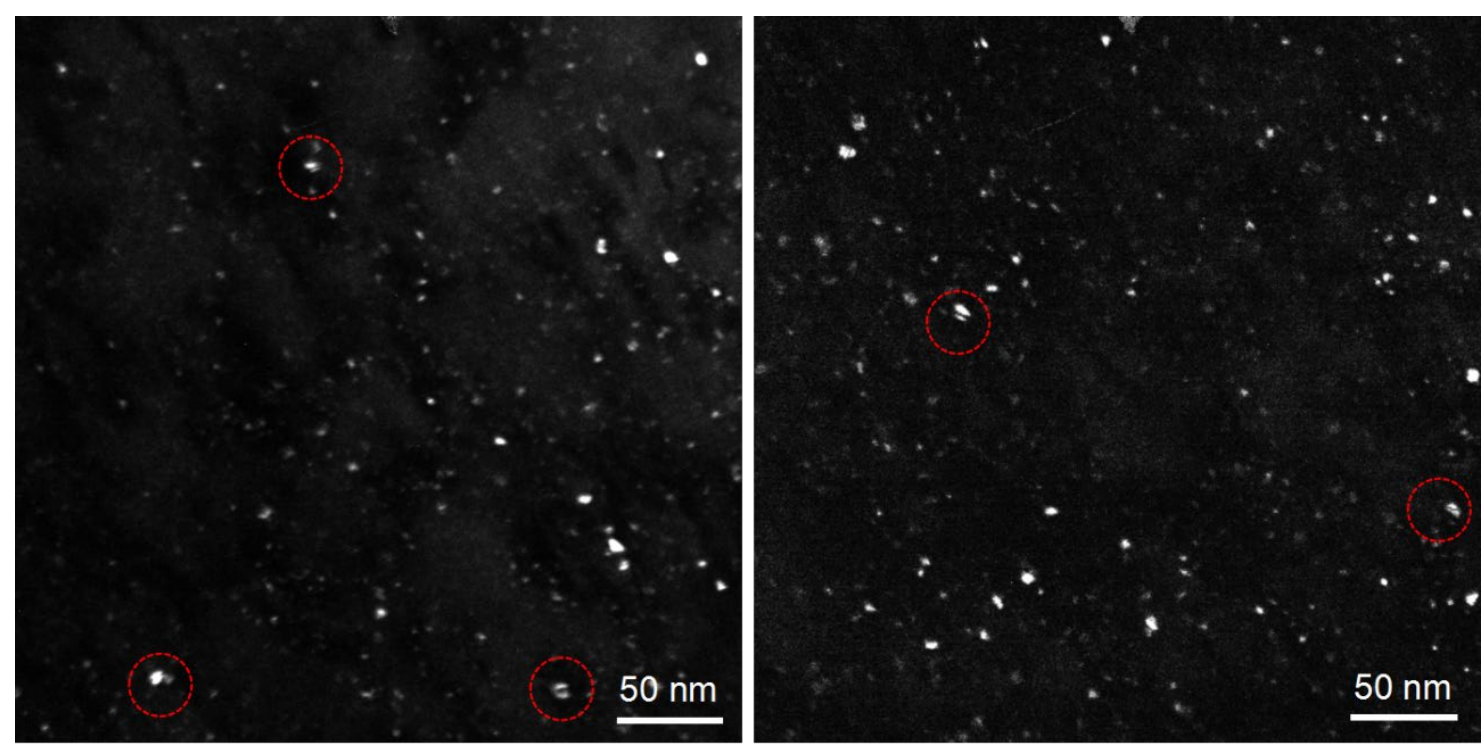

Fig. 10 Dark-field TEM showing the $\mathrm{Al}_{3}(\mathrm{Sc}, \mathrm{Zr})$ precipitates for $\mathrm{AlMgScZr}-623 \mathrm{~K} / 3 \mathrm{~h}$ alloy after $5 \%$ tensile strain. The zone axis is [011]. The dashed red circles clearly show that the precipitates are sheared by dislocations. 

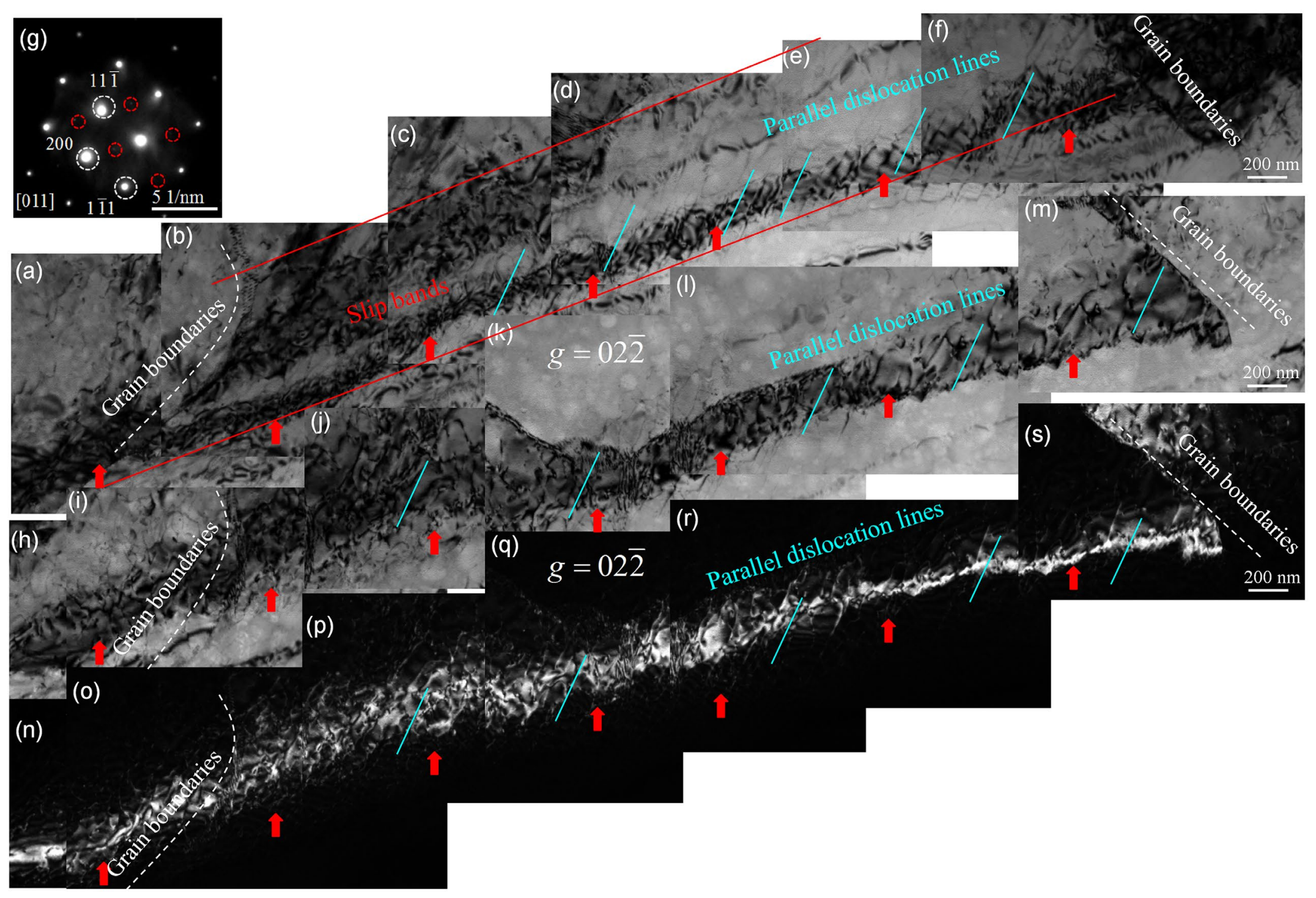
Fig. 11 TEM images of dislocation structure for AlMgScZr-623K/3h alloy with shearable precipitates after 5\% tensile strain: (a-f) bright TEM images of slip bands with [011] zone axis; (g) is the corresponding SAED of (a-f); (h-m) bright TEM images of slip bands with dual beam diffraction $(\mathrm{g}=02 \overline{2})$; (n-s) corresponding dark TEM images of $(\mathrm{h}-\mathrm{m})$ with dual beam diffraction $(\mathrm{g}=02 \overline{2})$. Here the red full lines in (a-f) refer to the slip bands due to dislocation shearing precipitates. The slip bands labelled by red arrows in the (a-f), (g-l) and (m-s) are the same slip bands. The cyan dotted lines refer to the parallel dislocation lines, and the dashed white lines denote grain boundaries.
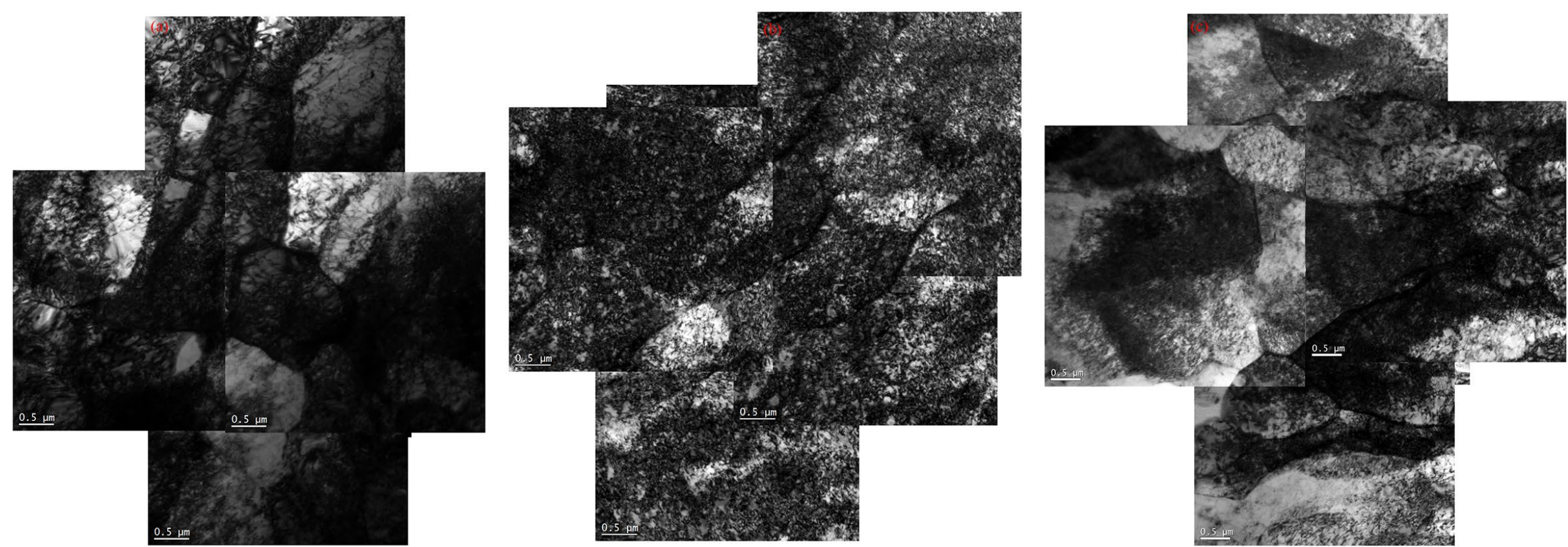

Fig. 12 Bright TEM images of dislocation structure for (a) AlMg (without precipitates), (b) AlMgScZr-773K/3h (with nonshearable precipitates) and (c) AlMgScZr-813K/24h (with nonshearable precipitates) alloys after 5\% tensile strain. The TEM images of these three alloys are acquired with the [011] zone axis. The dislocations of above three alloys distribute relative uniformly compared with AlMgScZr-623K/3h alloy. 
The TEM images of all samples after 5\% tensile strain are presented to demonstrate the magnitude of dislocation density and dislocation distribution after tensile deformation (Figs. 11 and 12). For AlMgScZr-623K/3h alloy, after tensile deformation, lots of slip bands is observed in microstructure, and dislocations pile up inside these slip bands. It is reasonable to infer that the retained dislocations during hot extrusion can move along a specific direction to form slip bands due to the shearing mechanism between precipitates and dislocations (this process may also contain lots of new dislocations generated during tension). On the other hand, once the dislocations move and form slip bands, these dislocations are difficult to be annihilated during tension. This is because most of these dislocations inside slip bands have the same Burgers vector (most of dislocations lines are parallel, indicating that these dislocations are of same Burgers vector), thus they are difficult to be annihilated through cross-slip [Sandström, 1977; Nes, 1995; Xiao et al., 2005]. It should be noted that there are still a considerable number of dislocations outside the slip bands in AlMgScZr-623K/3h alloy, although its local density is much lower than that in slip bands. The measured dislocation density by SRXRD is total dislocation density, which contains the dislocations both inside slip bands and outside the slip bands. For $\mathrm{AlMg}$ and other AlMgScZr alloys, the dislocations distribute more uniformly (Fig. 12), these tangled dislocations usually have different Burgers vectors. Dislocation annihilation is easy to occur when dislocation tangles become complicated, which also limits the rapid increase of dislocation density [Verdier et al., 1998; Kocks and Mecking, 2003]. Thus, although alloys with nonshearable precipitates can accumulate lots of Orowan loops during tension, the total density of dislocations for a given microscopic tensile strain is much smaller (Fig. 13(f)) than in the case of shearable precipitates. The AlMgScZr-623K/3h alloy has the higher dislocation density than $\mathrm{AlMg}$ and the other AlMgScZr alloys is more related to the formation of slip bands (dislocations can be stored more effectively inside the local slip bands). 


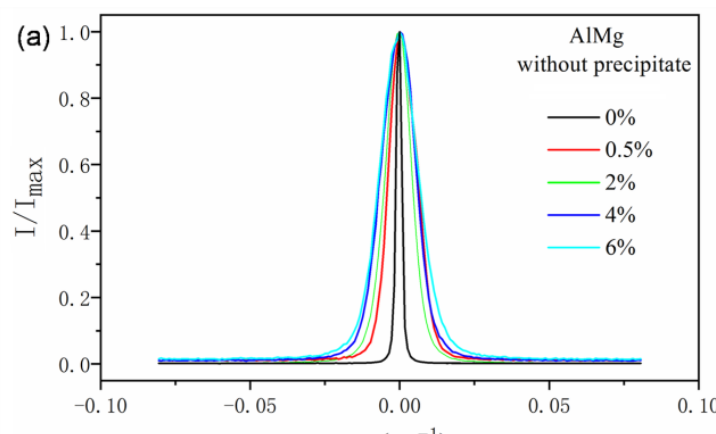

$\mathrm{q}\left(\mathrm{nm}^{-1}\right)$
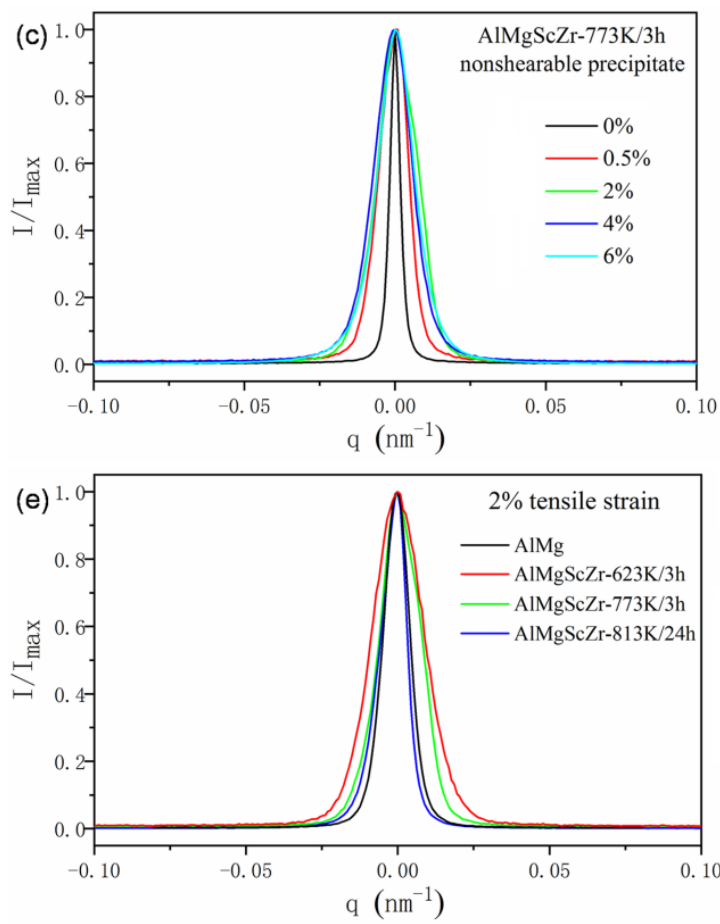

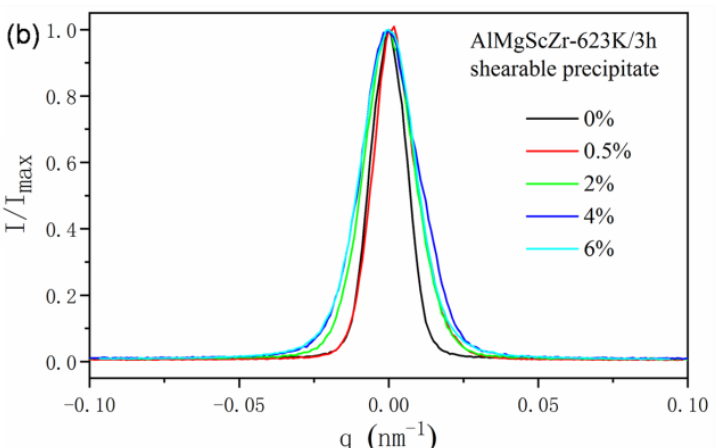

q $\left(\mathrm{nm}^{-1}\right)$
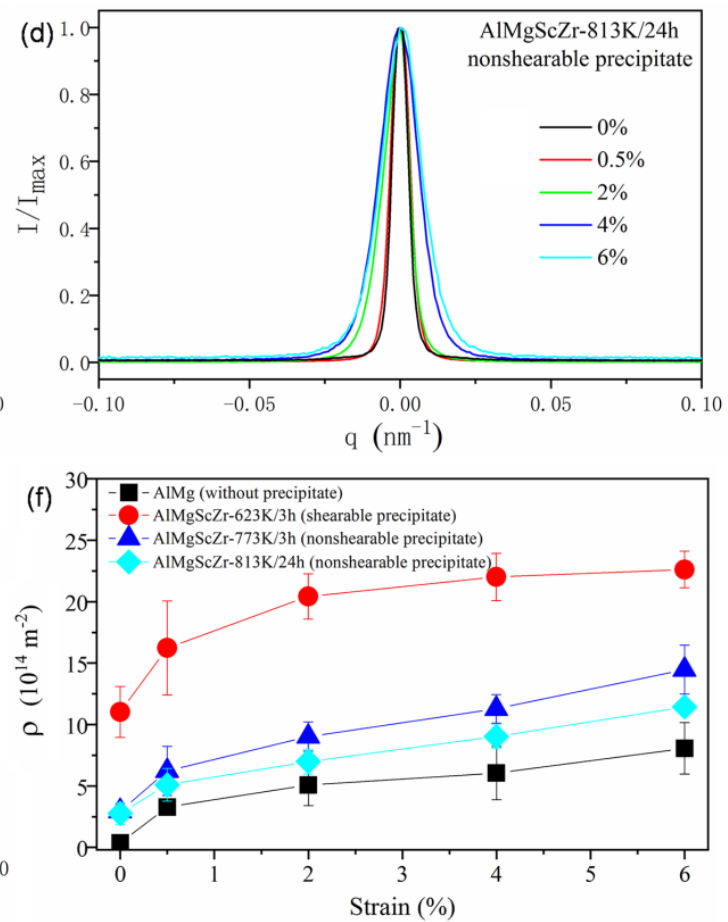

701

702

Fig. 13 Peaks profiles of AlMg and three AlMgScZr alloys as well as the quantitative measurement of dislocation density: (200) peaks profiles of (a) $\mathrm{AlMg}$, (b) AlMgScZr-623K/3h, (c) AlMgScZr-773K/3h, and (d) AlMgScZr-813K/24h after different tensile strains; (e) (200) peaks profiles of AlMg and three AlMgScZr alloys after $2 \%$ tensile strain; (f) variations of dislocation density versus tensile strain for 
$\mathrm{AlMg}$ and three AlMgScZr alloys. The dislocation density is measured averagely from (200), (220) and (311) peaks. Here the peaks profiles of (220) and (311) are omitted for simplicity, since they have similar features to the (200) peaks.

\subsection{Influence of precipitates on the characteristics of PLC bands}

The PLC is due to the interaction between solute atoms and dislocations, which is the process dominated by dislocation pinning and unpinning [Kubin and Estrin, 1985; Rizzi and Hähner, 2004]. However, the solute-dislocation interaction mechanisms for the appearance of PLC are different in normal and inverse behavior regimes [Chaenock, 1969; Soler-gomez and Tegart, 1969; McCormick et al., 1970, 1972b; Fu et al., 2012; Zhemchuzhnikova et al., 2015; Zhang et al., 2017; Geng et al., 2020]. In normal behavior regime (at higher strain rate), the mobile dislocations usually have a higher movement velocity and the solute atoms cannot capture the mobile dislocations due to their relatively lower diffusion rate. When the mobile dislocations are arrested by forest dislocations and other obstacles, the solute atoms have the possibility to capture the mobile dislocations. Only when the solute atoms diffuse to the arrested mobile dislocations during the waiting time does PLC occur. Thus, at normal behavior, the PLC appears in the condition of the solute atoms diffusing to the arrested mobile dislocations and pinning these dislocations. The stress strain curves usually exhibit locking serrations or steps (Figs. 5(a), (c)), and the PLC appears in the form of an abrupt rise. The abrupt rise indicates a process that the solute atoms pin the arrested mobile dislocations, also meaning that the solute atoms pinning the mobile dislocations leads to PLC. Therefore, at this time, the physical mechanism for controlling the appearance of PLC is defined as "dislocation pinning mechanism". On the contrary, in inverse behavior regime (at lower strain rate), the mobile dislocations can be pinned by solute atom atmosphere before the tensile plastic deformation due to the very low velocity of mobile dislocations. The critical condition for the appearance of PLC is the breakaway of mobile dislocations from this atmosphere, which is different from that in normal behavior regime [Chaenock, 1969; Soler-gomez and Tegart, 1969; McCormick et al., 1970, 1972b; Fu et al., 2012; Geng et al., 2020]. The stress strain curves usually manifest unlocking serrations (Fig. 5(f)) for inverse behavior, and the PLC appears in the form of a stress drop. The stress drop indicates a process that the mobile dislocations escape from the pinning of solute atmosphere, 
meaning that the escape of mobile dislocations from the existing atmosphere also leads to the PLC. The physical mechanism controlling the appearance of PLC is thus defined as "dislocation unpinning mechanism".

It is shown that precipitates influence the transition between $A+B / B$ and $C$ type bands: the corresponding strain rate firstly increases from $5.0 \times 10^{-4} \mathrm{~s}^{-1}$ to $2.5 \times 10^{-3} \mathrm{~s}^{-1}$ for the AlMgScZr-623K/3h alloy with shearable precipitates followed by a decrease from $2.5 \times 10^{-3} \mathrm{~s}^{-1}$ to $7.5 \times 10^{-4} \mathrm{~s}^{-1}$ when shearable precipitates become nonshearable precipitates (Figs. 6(a-d)). These results show that precipitates increase the lower strain rate for the occurrence of type $\mathrm{C}$ band. Our results are similar to Cai et al. who manifested that precipitates increase the lower strain rate for the appearance of type $\mathrm{C}$ band in Ni-based superalloys [Cai et al., 2015, 2017]. Regarding as sites where the dislocations pile up (Fig. 11), shearable precipitates increase the internal stress and favor a change from type $\mathrm{B}$ band to type $\mathrm{C}$ band with the decrease of strain rate (Figs. 6(a-d)). The shearable precipitates strongly influence the dynamical mechanisms of local strain propagation, through the localization of dislocation glide (Fig. 11) [Mogucheva et al., 2016].

The type $\mathrm{C}$ bands are a kind of dislocation unlocking serrations due to the unpinning mechanism between mobile dislocation and solute atoms, while type A and $\mathrm{B}$ bands are caused by dislocation pinning mechanism. Shearable precipitates increase the lower strain rate for the formation of type $\mathrm{C}$ band (Fig. 6(a-d)), meaning that the shearable precipitates increase the critical strain rate between dislocation unpinning and pinning mechanisms. It is because that, at same strain rate, the high local dislocation density in alloy containing shearable precipitates could enhance the diffusion rate of solute atoms (Fig. 13(f)). On one hand, the higher density of dislocation can reduce the diffusion activation energy and thus enhances the diffusion velocity [Legros et al., 2008]. On the other hand, the substitutional solute migration is correlated with the vacancy concentration [Picu and Zhang, 2004; Picu and Xu, 2007; Van der Ven et al., 2010]. As such systems with larger dislocation content are more likely to exhibit local vacancy supersaturation which will aid diffusion [Van der Ven et al., 2010]. When the diffusion rate of solute atoms increases, it is much easier to meet the condition of dislocation unpinning (i.e. the diffusion rate of solute atoms is much higher than the velocity of mobile dislocations). At this time, there is no need to decrease the movement velocity of mobile dislocation to meet dislocation unpinning via decreasing the strain rate. Therefore, the shearable precipitates increase the critical 
strain rate between unpinning and pinning mechanisms by increasing local dislocation density for a given microscopic strain. However, these effects (increasing the lower strain rate for the formation of type $\mathrm{C}$ band and increasing the critical strain rate between unpinning and pinning mechanisms) weakens due to the decrease of stored dislocation density when shearable precipitates become nonshearable precipitates (Figs. 6(a-d) and Table 2).

As far as the serration amplitude is concerned, the appearance of precipitates increases the magnitude of serration amplitude no matter for normal behavior (Fig. 7) or inverse behavior (Fig. 8). The serration amplitude $\Delta \sigma$ can be expressed as [Chen et al., 1996; Zhang et al., 2017]:

$\Delta \sigma \propto\left[\dot{\varepsilon}^{-1} \varepsilon^{\beta(1 / 2+\gamma)} d^{-n(1 / 2+\gamma)} T^{-1} \exp (-Q / k T)\right]^{2 / 3}$

where $\dot{\varepsilon}$ is strain rate; $\varepsilon$ is strain; $d$ is the grain size; $T$ is temperature; $Q$ is the activation energy for solute diffusion, which is associated with solute-vacancy site exchange; $k$ is the Boltzmann constant. Precipitates enhance the accumulation of dislocation density, which can reduce $Q$ and thus accelerate the diffusion of atoms [Legros et al., 2008]. Therefore, it is reasonable to infer that the $\Delta \sigma$ increases for AlMgScZr alloy with precipitates in contrast to AlMg alloy based on Eq. (7). By comparing the samples with shearable and nonshearable precipitates, the shearable precipitates can reduce $Q$ obviously by storing more dislocations, leading to a larger serration amplitude.

\subsection{Influence of precipitates on normal and inverse behaviors}

Since the solute-dislocation interactions for the appearance of PLC at normal and inverse behaviors are related to the dislocation pinning and unpinning mechanisms, respectively [Chaenock, 1969; Soler-gomez and Tegart, 1969; McCormick et al., 1970, 1972b; Fu et al., 2012; Geng et al., 2020]. The introduction of shearable precipitates and nonshearable precipitates have different effects on different solute-dislocation interactions, which are discussed as follows.

\subsubsection{Influence of precipitates on normal behavior}

At higher strain rates, the locking serration (type A and B bands) or upward step 
805 (type A bands) demonstrates that mobile dislocations are not pinned by diffusing solute atoms at the beginning of tensile deformation [Chaenock, 1969; Soler-gomez and Tegart, 1969; McCormick et al., 1970, 1972b; Fu et al., 2012; Geng et al., 2020]. When the mobile dislocations are captured by diffusing solute atoms, the PLC occurs. For the AlMg alloy mobile dislocations are mainly pinned by forest dislocations, while in AlMgScZr the mobile dislocations are pinned both by forest dislocations and precipitates together. When the shearable precipitates are present, the mobile dislocations will be additionally pinned until they can find a partner dislocation to form the superdislocations and cut through the precipitates. Thus, the pinning effect on mobile dislocations increases evidently when the shearable precipitates appear. As a consequence, the waiting time $t_{w}$ also increases obviously. When shearable precipitates become nonshearable, the mobile dislocations will be additionally pinned until they pass through the precipitates. Compared with the shearable precipitates, the pinning effect on mobile dislocations provided by nonshearable precipitates weakens (Fig. 9 and Table 3). Thus, the waiting time $t_{w}$ decreases with the shearable precipitates transforming to nonshearable. Here $t_{w}$ refers to the time during which the mobile dislocations are arrested by obstacles, which is given by [Bréchet and Estrin, 1995; Curtin et al., 2006]:

$t_{w}=\Omega / \dot{\varepsilon}=\rho_{m} b L / \dot{\varepsilon}$

where $\Omega$ is elementary plastic strain [Bréchet and Estrin, 1995]; $\rho_{m}$ is denoted as mobile dislocations; $b$ is Burgers vector; $L$ is the average spacing between obstacles, representing the flight distance of solute atom migration; $\dot{\varepsilon}$ is the strain rate. Compared to the AlMg alloy, the waiting time $t_{w}$ of mobile dislocations in AlMgScZr alloy with shearable precipitates increases, which indicates that the solute atoms have more time to capture the arrested mobile dislocations. At this time, there is no need to enhance the diffusion velocity of solute atoms by imposing a higher tensile strain, and thus the onset strain of PLC decreases. When the shearable precipitates transform into nonshearable precipitates, the waiting time $t_{w}$ decreases, and the solute atoms need a higher diffusion velocity in order to capture the arrested mobile dislocations. At this time, a relative higher tensile strain is required for generating more vacancies to enhance diffusion velocity of solute atoms, thus the onset strain increases. In summary, the presence of shearable precipitates and their 
subsequent transforming into nonshearable precipitates make the imposed onset strain to meet the pinning requirement first decreased and then increased at high strain rates, as shown in Figs. 6(e-h).

\subsubsection{Influence of precipitates on inverse behavior}

At lower strain rates, the unlocking serration (type $\mathrm{C}$ band) indicates that mobile dislocations are pinned before tensile plastic deformation. When the mobile dislocations escape from pinning obstacles, the PLC occurs [Chaenock, 1969; Soler-gomez and Tegart, 1969; McCormick et al., 1970, 1972b; Fu et al., 2012; Geng et al., 2020]. Thus the PLC phenomenon will occur after a certain degree of tensile plastic deformation. In the process of mobile dislocations overcoming obstacles, the mobile dislocations need to overcome the energy barrier. It is obvious that the energy barrier will increase due to the introduction of precipitates and the strain rate for the onset of PLC will increase correspondingly. The results in sections 4.1 and 4.2 have proved that the shearable precipitates improve the strength and store a higher density of dislocation density, indicating that the applied stress will be increased if the mobile dislocations expect to overcome the energy barriers. However, the inhibition effects decrease due to the shearable precipitates becoming nonshearable precipitates, and as a result the energy barrier will be decreased due to the weaker precipitate-dislocation interaction (the subsequent decrease of strength and dislocation density can prove it (Figs. 9 and 13)). Hence, the shearable precipitates will make the low critical strain rate for the occurrence of PLC increased evidently, and this low critical strain rate will decrease with the shearable precipitates being replaced by nonshearable precipitates. This explains that the shearable precipitates firstly narrow the strain-rate ranges for the appearance of PLC and then expands this strain-rate range with the shearable precipitates becoming nonshearable (Fig. 6(a-d) and Table 2). For the onset strain, if the strain rate is same, the first increase and then decrease of energy barriers by introducing shearable precipitates and subsequent growing into nonshearable precipitates result in the corresponding variations of onset strain. It is because dislocations can escape the higher energy barrier only by increasing onset strain to provide a higher stress. Therefore, at inverse behavior regime, the shearable precipitates first enlarge the critical strain for the appearance of PLC and then decreases this strain when shearable precipitates become nonshearable precipitates 
(Figs. 6(i-1)).

It should be noted that the process of dislocation shearing small precipitates is influenced by thermal activation for AlMgScZr-623K/3h alloy according to Argon's study [Argon, 2008]. At higher strain rate, the mobile dislocations have a higher movement velocity, which is easier to cutting the precipitates and overcome the energy barrier, since the mobile dislocations have a higher kinetic energy. Thus, at this time, the dislocations have a higher cutting rate, and the waiting time provided by precipitates will decrease to some extent.

\section{Conclusions}

In this study, we systematically investigate the influence of shearable and nonshearable $\mathrm{Al}_{3}(\mathrm{Sc}, \mathrm{Zr})$ precipitates on PLC behavior for precipitation hardening $\mathrm{AlMgScZr}$ alloys. It is shown that the presence of precipitates, as well as the change of the precipitate-dislocation interaction mechanism leads to different PLC behavior. The main conclusions are the following:

(1) Shearable precipitates promote the formation of slip bands with dislocation pile-ups due to their precipitate-dislocation interaction, while the dislocations distribute relatively uniformly in samples containing nonshearable precipitates. Compared with the samples with nonshearable precipitates, the higher local strain rate and higher local strain caused by shearable precipitates make more dislocations retained in samples, leading to a higher dislocation storage.

(2) Shearable precipitates increase the lower strain rate for the appearance of type C band, but this effect decreases with the shearable precipitates becoming nonshearable precipitates. Shearable precipitates enhance the serration amplitude largely, but the serration amplitude decreases when shearable precipitates become nonshearable precipitates. Both above phenomena are attributed to the first increase and then decrease of dislocation density controlled by different dislocation-precipitate interactions.

(3) At higher strain rates, the shearable precipitates decrease the onset strain but the onset strain then increases when shearable precipitates become nonshearable 
precipitates, which is due to the first increase and then decrease of waiting time controlled by different precipitates. At lower strain rates, the shearable precipitates increase the onset strain but the onset strain then decreases with the shearable precipitates being replaced by nonshearable precipitates, which is due to the first increase and then decrease of energy barrier which needs to be overcome.

(4) Shearable precipitates narrow the strain-rate range of PLC, but this strain-rate range expands again when shearable precipitates are replaced by nonshearable precipitates. That is because the lower critical strain rate being dominated by the precipitate-induced energy barrier first increases and then decreases.

(5) At higher strain rates, precipitates act as additional obstacles, along with forest dislocations, to arrest mobile dislocations. Solute atoms thus have more time to diffuse onto arrested mobile dislocations, leading to a decrease of onset strain, i.e., precipitates facilitate dislocation pinning process. At lower strain rate, additional pinning effect provided by precipitates results in a higher required applied stress for arrested mobile dislocations to escape from the pinning of atmosphere, leading to an increase of onset strain, i.e., precipitates prevent dislocation unpinning process. Both of the above effects attenuate with the shearable precipitates becoming nonshearable precipitates.

\section{Acknowledgement}

This work is financially supported by the National Natural Science Foundation of China [Grant Nos. 51971137, 11875192, and U1930101] and the Conseil Regional du Nord-Pas de Calais and the European Regional Development Fund (ERDF). This work was also partially supported by le ministère de l'Europe et des Affaires étrangè res in France. Yubin Ke is also grateful for the funding from the Natural Science Foundation of Guangdong Province (CN) [Grant No. 2018A030313728] and the

National Key Research and Development Program of China [Grant No. 2016YFA0401501]. We would also like to thank the faculty of BL14B1 beamline at the Shanghai Synchrotron Radiation Facility for their help with synchrotron experiments. Han Chen is grateful for the support from the Tescan, China. 


\section{References}

Aboulfadl, H., Deges, J., Choi, P., Raabe, D., 2015. Dynamic strain aging studied at the atomic scale. Acta Mater. 86, 34-42. https://doi.org/10.1016/j.actamat.2014.12.028.

Aifantis, E.C., 1987. The physics of plastic deformation. Int. J. Plast. 3, 211-247. https://doi.org/10.1016/0749-6419(87)90021-0.

Ait-Amokhtar, H., Boudrahem, S., Fressengeas, C., 2006a. Spatiotemporal aspects of jerky flow in Al-Mg alloys, in relation with the $\mathrm{Mg}$ content. Scr. Mater. 54, 2113-2118. https://doi.org/10.1016/j.scriptamat.2006.03.006.

Ait-Amokhtar, H., Vacher, P., Boudrahem, S., 2006b. Kinematics fields and spatial activity of Portevin-Le Chatelier bands using the digital image correlation method. Acta Mater. 54, 4365-4371. https://doi.org/10.1016/j.actamat.2006.05.028.

Alinaghian, Y., Asadi, M., Weck, A., 2014. Effect of pre-strain and work hardening rate on void growth and coalescence in AA5052. Int. J. Plast. 53, 193-205. https://doi.org/10.1016/j.ijplas.2013.08.007.

Antolovich, S.D., Armstrong, R.W., 2014. Plastic strain localization in metals: origins and consequences. Prog. Mater. Sci. 59, 1-160. https://doi.org/10.1016/j.pmatsci.2013.06.001.

Ardell, A.J., 1985. Precipitation hardening. Metall. Trans. 16A, 2131-2165. https://doi.org/10.1007/BF02670416.

Aretz, H., 2007. Numerical analysis of diffuse and localized necking in orthotropic sheet metals. Int. J. Plast. 23, 798-840. https://doi.org/10.1016/j.ijplas.2006.07.005. Argon, A.S., 2008. Strengthening mechanisms in crystal plasticity. Oxford University Press. Barnett, M.R., Wang, H., Guo, T.T., 2019. An Orowan precipitate strengthening equation for mechanical twinning in Mg. Int. J. Plast. 112, 108-122. https://doi.org/10.1016/j.ijplas.2018.08.010.

Benallal, A., Berstad, T., Børvik, T., Hopperstad, O.S., Koutiri, I., Nogueira de Codes, R., 2008. An experimental and numerical investigation of the behaviour of AA5083 aluminium alloy in presence of the Portevin-Le Chatelier effect. Int. J. Plast. 24, 1916-1945. https://doi.org/10.1016/j.ijplas.2008.03.008.

Böhlke, T., Bondár, G., Estrin, Y., Lebyodkin, M.A., 2009. Geometrically non-linear modeling of the Portevin-Le Chatelier effect. Comp. Mater. Sci. 44, 1076-1088. https://doi.org/10.1016/j.commatsci.2008.07.036.

Borbély, A., Groma, I., 2001. Variance method for the evaluation of particle size and dislocation density from x-ray Bragg peaks. Appl. Phys. Lett. 79, 1772-1774. https://doi.org/10.1063/1.1404134.

Bréchet, Y., Louchet, F., 1990. Precipitation hardening and strain localization: instabilities induced by geometrical shearing or by chemical reversion. J. Mech. Behav. Mater. 2, 335-352. https://doi.org/10.1515/JMBM.1989.2.3-4.335.

Bréchet, Y., Estrin, Y., 1995. On the influence of precipitation on the Portevin-Le Chatelier effect. Acta Metall. Mater. 43, 955-963. https://doi.org/10.1016/0956-7151(94)00334-E.

Cai, Y.L., Tian, C.G., Fu, S.H., Han, G.M., Cui, C.Y., Zhang, Q.C., 2015. Influence of $\gamma^{\prime}$ precipitates on Portevin-Le Châtelier effect of Ni-based superalloys. Mater. Sci. Eng. A 638, 314-321. https://doi.org/10.1016/j.msea.2015.04.033.

Cai, Y.L., Tian, C.G., Zhang, G.L., Han, G.M., Yang, S.L., Fu, S.H., Cui, C.Y., Zhang, Q.C., 2017. Influence of $\gamma^{\prime}$ precipitates on the critical strain and localized deformation of serrated flow in $\begin{array}{llllll}\text { Ni-based } & \text { superalloys. } & \text { J. } & \text { Alloy. Compd. } & \text { 690, }\end{array}$ https://doi.org/10.1016/j.jallcom.2016.08.194. 
Chaenock, W., 1969. The initiation of serrated yielding at elevated temperatures. Philos. Mag. 20, 427-432. https://doi.org/10.1080/14786436908228714.

Chen, H., Chen, Z., Ji, G., Zhong, S.Y., Wang, H.W., Borbély, A., Ke, Y.B., Bréchet, Y., 2021. Experimental and modelling assessment of ductility in a precipitation hardening AlMgScZr alloy. Int. J. Plast. 139, 102971. https://doi.org/10.1016/j.ijplas.2021.102971.

Chen, M.C., Chen, L.H., Lui, T.S., 1996. Analysis on the amplitude of serrated flow associated with the Portevin-Le Chatelier effect of substitutional fcc alloys. Metall. Mater. Trans. A 27A, 1691-1694. https://doi.org/10.1007/bf02649826.

Chmelík, F., Pink, E., Król, J., Balík, J., Pešička, J., Lukáč, P., 1998. Mechanisms of serrated flow in aluminium alloys with precipitates investigated by acoustic emission. Acta Mater. 46, 4435-4442. https://doi.org/10.1016/S1359-6454(98)00070-6.

Clouet, E., Barbu, A., Laé, L., Martin, G., 2005. Precipitation kinetics of $\mathrm{Al}_{3} \mathrm{Zr}$ and $\mathrm{Al}_{3} \mathrm{Sc}$ in aluminum alloys modeled with cluster dynamics. Acta Mater. 53, 2313-2325. https://doi.org/10.1016/j.actamat.2005.01.038.

Clouet, E., Laé, L., Épicier, T., Lefebvre, W., Nastar, M., Deschamps, A., 2006. Complex precipitation pathways in multicomponent alloys. Nat. Mater. 5, 482-488. https://doi.org/10.1038/nmat1652.

Cottrell, A.H., Bilby, B.A., 1949. Dislocation theory of yielding and strain ageing of iron. Proc. Phys. Soc. A 62, 49-62. https://doi.org/10.1088/0370-1298/62/1/308.

Curtin, W.A., Olmsted, D.L., Hector Jr, L.G., 2006. A predictive mechanism for dynamic strain ageing in aluminium-magnesium alloys. Nat. Mater. 5, 875-880. https://doi.org/10.1038/nmat1765.

Deschamps, A., Geuser, F.D., 2011. On the validity of simple precipitate size measurements by small-angle scattering in metallic systems. J. Appl. Crystallogr. 44, 343-352. https://doi.org/10.1107/S0021889811003049.

Deschamps, A., Lae, L., Guyot, P., 2007. In situ small-angle scattering study of the precipitation kinetics in an Al-Zr-Sc alloy. Acta Mater. 55, 2775-2783. https://doi.org/10.1016/j.actamat.2006.12.015.

Dierke, H., Krawehl, F., Graff, S., Forest, S., Šachl, J., Neuhäuser, H., 2007. Portevin-Le Chatelier effect in Al-Mg alloys: Influence of obstacles - experiments and modelling. Com. Mater. Sci. 39, 106-112. https://doi.org/10.1016/j.commatsci.2006.03.019.

Duan, Y.X., Chen, H., Chen, Z., Wang, L., Wang, M.L., Liu, J., Zhang, F.G., Wang, H.W., 2021. The influence of nanosized precipitates on Portevin-Le Chatelier bands and surface roughness in AlMgScZr alloy. J. Mater. Sci. Technol. 87, 74-82. https://doi.org/10.1016/j.jmst.2021.01.044.

Estrin, Y., Kubin, L.P., 1990. Collective dislocation behaviour in dilute alloys and the Portevin-Le Châtelier effect. J. Mech. Behav. Mater. 255-292. https://doi.org/10.1515/JMBM.1989.2.3-4.255.

Estrin, Y., Kubin, L.P., 1991. Plastic instabilities: phenomenology and theory. Mater. Sci. Eng. A 137, 125-134. https://doi.org/10.1016/0921-5093(91)90326-I.

Estrin, Y., Kubin, L.P., 1995. Spatial coupling and propagative plastic instabilities. In H. B. Muhlhaus (Ed.), continuum models for materials with microstructure. New York: John Wiley \& Sons Ltd.

Fan, H.D., Ngan, A.H.W., Gan, K.F., El-Awady, J.A., 2018. Origin of double-peak precipitation hardening in metallic alloys. Int. J. Plast. 111, 152-167. https://doi.org/10.1016/j.ijplas.2018.07.016.

Fazeli, F., Poole, W.J., Sinclair, C.W., 2008. Modeling the effect of $\mathrm{Al}_{3} \mathrm{Sc}$ precipitates on the yield 
stress and work hardening of an Al-Mg-Sc alloy. Acta Mater. 56, 1909-1918. https://doi.org/10.1016/j.actamat.2007.12.039.

Fressengeas, C., Beaudoin, A.J., Lebyodkin, M., Kubin, L.P., Estrin, Y., 2005. Dynamic strain aging: A coupled dislocation-Solute dynamic model. Mater. Sci. Eng. A 400-401, 226-230. https://doi.org/10.1016/j.msea.2005.02.073.

Fu, S.H., Cheng, T., Zhang, Q.C., Hu, Q., Cao, P.T., 2012. Two mechanisms for the normal and inverse behaviors of the critical strain for the Portevin-Le Chatelier effect. Acta Mater. 60, 6650-6656. https://doi.org/10.1016/j.actamat.2012.08.035.

Fuller, C.B., Seidman, D.N., Dunand, D.C., 2003. Mechanical properties of Al(Sc, Zr) alloys at ambient and elevated temperatures. Acta Mater. 51, 4803-4814. https://doi.org/10.1016/S1359-6454(03)00320-3.

Geng, Y.X., Zhang, D., Zhang, J.S., Zhuang, L.Z., 2020. Zn/Cu regulated critical strain and serrated flow behavior in Al-Mg alloys. Mater. Sci. Eng. A 795, 139991. https://doi.org/10.1016/j.msea.2020.139991.

Gladman, T., 1999. Precipitation hardening in metals. Mater. Sci. Technol. 15, 30-36. https://doi.org/ 10.1179/026708399773002782.

Hähner, P., 1997. On the critical conditions of the Portevin-Le Châtelier effect. Acta Mater. 45, 3695-3707. https://doi.org/10.1016/s1359-6454(97)00066-9.

Halim, H., Wilkinson, D.S., Niewczas, M., 2007. The Portevin-Le Chatelier (PLC) effect and shear band formation in an AA5754 alloy. Acta Mater. 55, 4151-4160. https://doi.org/10.1016/j.actamat.2007.03.007.

Hayes, R.W., Hayes, W.C., 1982. On the mechanism of delayed discontinuous plastic flow in an age-hardened nickel alloy. Acta Metall. 30, 1295-1301. https://doi.org/10.1016/0001-6160(82)90148-1.

Hayes, R.W., Hayes, W.C., 1984. A proposed model for the disappearance of serrated flow in two Fe alloys. Acta Metall. 32, 259-267. https://doi.org/10.1016/0001-6160(84)90054-3.

Hu, Q., Zhang, Q.C., Cao, P.T., Fu, S.H., 2012. Thermal analyses and simulations of the type A and type B Portevin-Le Chatelier effects in an Al-Mg alloy. Acta Mater. 60, 1647-1657. https://doi.org/10.1016/j.actamat.2011.12.003.

Hull, D., Bacon, D.J., 2011. Introduction to dislocations, fifth ed. Elsevier.

Humphreys, F.J., Hatherly, M., 2004. Recrystallization and related annealing phenomena, Second ed. Elsevier.

Iwamura, S., Miura, Y., 2004. Loss in coherency and coarsening behavior of $\mathrm{Al}_{3} \mathrm{Sc}$ precipitates. Acta Mater. 52, 591-600. https://doi.org/ 10.1016/j.actamat.2003.09.042.

Jaladurgam, N.R., Li, H.J., Kelleher, J., Persson, C., Steuwer, A., Colliander, M.H., 2020. Microstructure-dependent deformation behaviour of a low $\gamma^{\prime}$ volume fraction Ni-base superalloy studied by in-situ neutron diffraction. Acta Mater. 183, 182-195. https://doi.org/10.1016/j.actamat.2019.11.003.

Jiang, H.F., Zhang, Q.C., Chen, X.D., Chen, Z.J., Jiang, Z.Y., Wu, X.P., Fan, J.H., 2007. Three types of Portevin-Le Chatelier effects: Experiment and modelling. Acta Mater. 55, 2219-2228. https://doi.org/ 10.1016/j.actamat.2006.10.029.

Kalácska, S., Groma, I., Borbély, A., Ispánovity, P.D., 2017. Comparison of the dislocation density obtained by HR-EBSD and X-ray profile analysis. Appl. Phys. Lett. 110, 091912. https://doi.org/10.1063/1.4977569.

Kang, J., Wilkinson, D.S., Jain, M., Embury, J.D., Beaudoin, A.J., Kim, S., Mishira, R., Sachdev, A.K., 2006. On the sequence of inhomogeneous deformation processes occurring during tensile 
deformation of strip cast AA5754. Acta Mater. 54, 209-218. https://doi.org/10.1016/j.actamat.2005.08.045.

Ke, Y.B., He, C.Y., Zheng, H.B., Geng, Y.S., Fu, J.Y., Zhang, S.K., Hu, H.T., Wang, S.L., Zhou, B., Wang, F.W., Tao, J.Z., 2018. The time-of-flight small-angle neutron spectrometer at China spallation neutron source. Neutron

News,

29 ,

14-17. https://doi.org/10.1080/10448632.2018.1514197. ductility loss in aluminium-magnesium alloys due to dynamic strain aging. Nat. Commun. 5, 4604. https://doi.org/10.1038/ncomms5604. 2004. Analysis of Portevin-Le Chatelier serrations of type B in Al-Mg. Mater. Sci. Eng. A 369, 76-81. https://doi.org/10.1016/j.msea.2003.10.292.

Klusemann, B., Fischer, G., Böhlke, T., Svendsen, B., 2015. Thermomechanical characterization of Portevin-le châtelier bands in AlMg3 (AA5754) and modeling based on a modified $\begin{array}{llllll}\text { Estrin-McCormick } \quad \text { approach. } & \text { Int. } \quad \text { J. } & \text { Plast. } & 67, & \text { 192-216. }\end{array}$ https://doi.org/10.1016/j.ijplas.2014.10.011. evolution in $\mathrm{Al}-0.1 \mathrm{Sc}, \mathrm{Al}-0.1 \mathrm{Zr}$ and $\mathrm{Al}-0.1 \mathrm{Sc}-0.1 \mathrm{Zr}$ (at.\%) alloys during isochronal aging. Acta Mater. 58, 5184-5195. https://doi.org/10.1016/j.actamat.2010.05.054.

Knipling, K.E., Seidman, D.N., Dunand, D.C., 2011. Ambient- and high-temperature mechanical properties of isochronally aged $\mathrm{Al}-0.06 \mathrm{Sc}, \mathrm{Al}-0.06 \mathrm{Zr}$ and $\mathrm{Al}-0.06 \mathrm{Sc}-0.06 \mathrm{Zr}$ (at.\%) alloys. Acta Mater. 59, 943-954. https://doi.org/10.1016/j.actamat.2010.10.017. Kocks, U.F., Mecking, H., 2003. Physics and phenomenology of strain hardening: the FCC case. Prog. Mater. Sci. 48, 171-273. https://doi.org/10.1016/S0079-6425(02)00003-8.

Kok, S., Bharathi, M.S., Beaudoin, A.J., Fressengeas, C., Ananthakrishna, G., Kubin, L.P., Lebyodkin, M., 2003. Spatial coupling in jerky flow using polycrystal plasticity. Acta Mater. 51, 3651-3662. https://doi.org/10.1016/s1359-6454(03)00114-9.

1100 Kubin, L.P., Chihab, K., Estrin, Y., 1988. The rate dependence of the Portevin-Le Chatelier effect. Acta Metall. 36, 2707-2018. https://doi.org/10.1016/0001-6160(88)90117-4.

Kubin, L.P., Estrin, Y., 1985. The Portevin-Le Chatelier effect in deformation with constant stress rate. Acta Metall. 33, 397-407. https://doi.org/10.1016/0001-6160(85)90082-3.

Kubin, L.P., Estrin, Y., 1990. Evolution of dislocation densities and the critical conditions for the Portevin-Le Châtelier effect. Acta Metall. Mater. 38, 697-708. https://doi.org/10.1016/0956-7151(90)90021-8.

Kumar, S., 1995. Inverse behaviour of the onset strain of serrated flow. Scr. Metall. Mater. 33, 81-86. https://doi.org/10.1016/0956-716X(95)00099-H.

Kumar, S., Król, J., Pink, E., 1996. Mechanism of serrated flow in binary Al-Li alloys. Scr. Mater. 35, 775-780. https://doi.org/10.1016/1359-6462(96)00218-7.

Kumar, S., McShane, H.B., 1993. Serrated yielding in Ai-Li alloys. Scr. Metall. Mater. 28, 1149-1154. https://doi.org/10.1016/0956-716X(93)90025-N.

Kumar, S., Pink, E., 1994. Effect of $\delta^{\prime}$ precipitates on serrated flow. Scr. Metall. Mater. 32, 749-753. https://doi.org/10.1016/0956-716X(95)91597-I.

Kumar, S., Pink, E., 1997. Serrated flow in aluminium alloys containing lithium. Acta Mater. 45, 5295-5301. https://doi.org/10.1016/S1359-6454(97)00149-3.

Lai, J., Zhang, Z., Chen, X.G., 2013. Precipitation strengthening of $\mathrm{Al}-\mathrm{B}_{4} \mathrm{C}$ metal matrix composites alloyed with Sc and Zr. J. Alloy. Compd. 552, 227-235. https://doi.org/ 
10.1016/j.jallcom.2012.10.096.

Lebyodkin, M., Dunin-Barkowskii, L., Bréchet, Y., Estrin, Y., Kubin, L.P., 2000. Spatio-temporal dynamics of the Portevin-Le Chatelier effect: Experiment and modelling. Acta Mater. 48, 2529-2541. https://doi.org/10.1016/s1359-6454(00)00067-7.

Lefebvre, W., Masquelier, N., Houard, J., Patte, R., Zapolsky, H., 2014. Tracking the path of dislocations across ordered $\mathrm{Al}_{3} \mathrm{Zr}$ nano-precipitates in three dimensions. Scr. Mater. 70, 43-46. https://doi.org/10.1016/j.scriptamat.2013.09.014.

Legros, M., Dehm, G., Arzt, E., Balk, T.J., 2008. Observation of giant diffusivity along dislocation cores. Science 319, 1646-1649. https://doi.org/10.1126/science.1151771.

Louat, N., 1981. On the theory of the Portevin-Le Chatelier effect. Scr. Metall. 15, 1167-1170. https://doi.org/10.1016/0036-9748(81)90290-8.

Luca, A.D., Seidman, D.N., Dunand, D.C., 2019. Effects of Mo and Mn microadditions on strengthening and over-aging resistance of nanoprecipitation-strengthened Al-Zr-Sc-Er-Si alloys. Acta Mater. 165, 1-14. https://doi.org/10.1016/j.actamat.2018.11.031.

Ma, K.K., Wen, H.M., Hu, T., Topping, T.D., Isheim, D., Seidman, D.N., Lavernia, E.J., Schoenung, J.M., 2014. Mechanical behavior and strengthening mechanisms in ultrafine grain precipitation-strengthened aluminum alloy. Acta Mater. 62, 141-155. https://doi.org/10.1016/j.actamat.2013.09.042.

Manach, P.Y., Thuillier, S., Yoon, J.W., Coër, J., Laurent, H., 2014. Kinematics of Portevin-Le Chatelier bands in simple shear. Int. J. Plast. 58, 66-83. https://doi.org/10.1016/j.ijplas.2014.02.005.

Marquis, E.A., Seidman, D.N., 2001. Nanoscale structural evolution of $\mathrm{Al}_{3} \mathrm{Sc}$ precipitates in $\mathrm{Al}(\mathrm{Sc})$ alloys. Acta Mater. 49, 1909-1919. https://doi.org/10.1016/s1359-6454(01)00116-1.

Marquis, E.A., Seidman, D.N., 2005. Coarsening kinetics of nanoscale $\mathrm{Al}_{3} \mathrm{Sc}$ precipitates in an A1-Mg-Sc alloy. Acta Mater. 53, 4259-4268. https://doi.org/10.1016/j.actamat.2005.05.025.

McCormick, P.G., 1970. The form and initiation of serrated yielding in an Al- $\mathrm{Mg}_{2} \mathrm{Si}$ alloy. Scr. Metall. 4, 221-224. https://doi.org/10.1016/0036-9748(70)90197-3.

McCormick, P.G., 1972a. A model for the Portevin-Le Chatelier effect in substitutional alloys. Acta Metall. 20, 351-354. https://doi.org/10.1016/0001-6160(72)90028-4.

McCormick, P.G. 1972b. The inverse Portevin-Le Chatelier effect in an Al-Mg-Si alloy. Scr. Metall. 6, 165-170. https://doi.org/10.1016/0036-9748(72)90270-0.

Ming, K.S., Bi, X.F., Wang, J., 2018. Realizing strength-ductility combination of coarse-grained $\mathrm{Al}_{0.2} \mathrm{Co}_{1.5} \mathrm{CrFeNi}_{1.5} \mathrm{Ti}_{0.3}$ alloy via nano-sized, coherent precipitates. Int. J. Plast. 100, 177-191. https://doi.org/10.1016/j.ijplas.2017.10.005.

Mogucheva, A., Yuzbekova, D., Kaibyshev, R., Lebedkina, T., Lebyodkin, M., 2016. Effect of grain refinement on jerky flow in an Al-Mg-Sc alloy. Metall. Mater. Trans. A 47A, 2093-2106. https://doi.org/10.1007/s11661-016-3381-2.

Mulford, R.A., Kocks, U.F., 1979. New observations on the mechanisms of dynamic strain aging and of jerky flow. Acta Metall. 27, 1125-1135. https://doi.org/10.1016/0001-6160(79)90130-5.

Nalawade, S.A., Sundararaman, M., Kishore, R., Shah, J.G., 2008. The influence of aging on the serrated yielding phenomena in a nickel-base superalloy. Scr. Mater. 59, 991-994. https://doi.org/10.1016/j.scriptamat.2008.07.004.

Nes, E., 1995. Recovery revisited. Acta Metall. Mater. 43, 2189-2207. https://doi.org/10.1016/0956-7151(94)00409-9.

Okle, P., Lin, J.D., Zhu, T.Y., Dunand, D.C., Seidman, D.N., 2019. Effect of micro-additions of 
Ge, In or Sn on precipitation in dilute Al-Sc-Zr alloys. Mater. Sci. Eng. A 739, 427-436. https://doi.org/10.1016/j.msea.2018.10.058.

Picu, R.C., 2004. A mechanism for the negative strain-rate sensitivity of dilute solid solutions. Acta Mater. 52, 3447-3458. https://doi.org/10.1016/j.actamat.2004.03.042.

Picu, R.C., Xu, Z.J., 2007. Vacancy concentration in Al-Mg solid solutions. Scr. Mater. 57, 45-48. https://doi.org/10.1016/j.scriptamat.2007.03.014.

Picu, R.C., Zhang, D., 2004. Atomistic study of pipe diffusion in Al-Mg alloys. Acta Mater. 52, 161-171. https://doi.org/10.1016/j.actamat.2003.09.002.

Pink, E., 1989. The effect of precipitates on characteristics of serrated flow in AlZn5Mg1. Acta Metall. 37, 1773-1781. https://doi.org/10.1016/0001-6160(89)90062-X.

Pink, E., Grinberg, A., 1981. Serrated flow in a ferritic stainless steel. Mater. Sci. Eng. 51, 1-8. https://doi.org/10.1016/0025-5416(81)90099-9.

Pink, E., Kumar, S., Tian, B.H., 2000. Serrated flow of aluminium alloys influenced by precipitates. Mater. Sci. Eng. A 280, 17-24. https://doi.org/10.1016/s0921-5093(99)00650-4.

Poole, W.J., Wang, X., Lloyd, D.J., Embury, J.D., 2005. The shearable-non-shearable transition in Al-Mg-Si-Cu precipitation hardening alloys: implications on the distribution of slip, work hardening and fracture. Philos. Mag. 85, 3113-3135. https://doi.org/10.1080/14786430500154935. Ren, S.C., Morgeneyer, T.F., Mazière, M., Forest, S., Rousselier, G., 2021. Effect of Lüders and Portevin-Le Chatelier localization bands on plasticity and fracture of notched steel specimens studied by DIC and FE simulations. Int. J. Plast. 136, 102880. https://doi.org/10.1016/j.ijplas.2020.102880.

Riley, D.M., McCormick, P.G., 1977. The effect of precipitation hardening on the Portevin-Le Chatelier effect in an Al-Mg-Si alloy. Acta Metall. 25, 181-185. https://doi.org/10.1016/0001-6160(77)90121-3.

Rizzi, E., Hähner, P., 2004. On the Portevin-Le Chatelier effect: theoretical modeling and numerical results. Int. J. Plast. 20, 121-165. https://doi.org/10.1016/s0749-6419(03)00035-4.

Robinson, J.M., 1994. Serrated flow in aluminium base alloys. Int. Mater. Rev. 39, 217-227. http://dx.doi.org/10.1179/imr.1994.39.6.217.

Robinson, J.M., Shaw, M.P., 1994. Microstructural and mechanical influences on dynamic strain aging phenomena. Int. Mater. Rev. 39, 113-122. https://doi.org/10.1179/imr.1994.39.3.113.

Rousselier, G., Quilici, S., 2015. Combining porous plasticity with Coulomb and Portevin-Le Chatelier models for ductile fracture analyses. Int. J. Plast. 69, 118-133. https://doi.org/10.1016/j.ijplas.2015.02.008.

Sandström, R., 1977. On recovery of dislocations in subgrains and subgrain coalescence. Acta Metall. 25, 897-904. https://doi.org/10.1016/0001-6160(77)90176-6.

Seidman, D.N., Marquis, E.A., Dunand, D.C., 2002. Precipitation strengthening at ambient and elevated temperatures of heat-treatable $\mathrm{Al}(\mathrm{Sc})$ alloys. Acta Mater. 50, 4021-4035. https://doi.org/10.1016/S1359-6454(02)00201-X.

Sharma, V.M.J., Sree Kumar, K., Nageswara Rao, B., Pathak, S.D., 2009. Studies on the work-hardening behavior of AA2219 under different aging treatments, Metall. Mater. Trans. A 40, 3186-3195. https://doi.org/10.1007/s11661-009-0062-4.

Shibkov, A.A., Gasanov, M.F., Zheltov, M.A., Zolotov, A.E., Ivolgin, V.I., 2016. Intermittent plasticity associated with the spatio-temporal dynamics of deformation bands during creep tests in an AlMg polycrystal. Int. J. Plast. 86, 37-55. https://doi.org/10.1016/j.ijplas.2016.07.014.

Soare, M.A., Curtin, W.A., 2008a. Solute strengthening of both mobile and forest dislocations: The origin of dynamic strain aging in fcc metals. Acta Mater. 56, 4046-4061. 
https://doi.org/10.1016/j.actamat.2008.04.027.

Soare, M.A., Curtin, W.A., 2008b. Single-mechanism rate theory for dynamic strain aging in fcc metals. Acta Mater. 56, 4091-4101. https://doi.org/10.1016/j.actamat.2008.04.030.

Soler-gomez, A.J.R., Tegart, W.J.M., 1969. Serrated flow in gold-indium alloys. Philos. Mag. 20, 495-509. https://doi.org/10.1080/14786436908228722.

Swaminathan, B., Abuzaid, W., Sehitoglu, H., Lambros, J., 2015. Investigation using digital image correlation of Portevin-Le Chatelier effect in Hastelloy X under thermo-mechanical loading. Int. J. Plast. 64, 177-192. https://doi.org/10.1016/j.ijplas.2014.09.001.

Taendl, J., Orthacker, A., Amenitsch, H., Kothleitner, G., Poletti, C., 2016. Influence of the degree of scandium supersaturation on the precipitation kinetics of rapidly solidified Al-Mg-Sc-Zr alloys. Acta Mater. 117, 43-50. https://doi.org/10.1016/j.actamat.2016.07.001.

Tayon, W.A., Nygren, K.E., Crooks, R.E., Pagan, D.C., 2019. In-situ study of planar slip in a commercial aluminum-lithium alloy using high energy X-ray diffraction microscopy. Acta Mater. 173, 231-241. https://doi.org/10.1016/j.actamat.2019.04.030.

Thevenet, D., Mliha-Touati, M., Zeghloul, A., 1999. The effect of precipitation on the Portevin-Le Chatelier effect in an Al-Zn-Mg-Cu alloy. Mater. Sci. Eng. A 266, 175-182. https://doi.org/10.1016/S0921-5093(99)00029-5.

Tsai, C.W., Lee, C., Lin, P.T., Xie, X., Chen, S.Y., Carroll, R., LeBlanc, M., Brinkman, B.A.W., Liaw, P.K., Dahmen, K.A., Yeh, J.W., 2019. Portevin-Le Chatelier mechanism in face-centered-cubic metallic alloys from low to high entropy. Int. J. Plast. 122, 212-224. https://doi.org/10.1016/j.ijplas.2019.07.003.

Van den Beukel, A., 1975. Theory of the effect of dynamic strain aging on mechanical properties. Phys. Stat. Sol. (a) 30, 197-206. https://doi.org/10.1002/pssa.2210300120.

Van der Ven, A., Yu, H.C., Ceder, G., Thornton, K., 2010. Vacancy mediated substitutional diffusion in binary crystalline solids. Prog. Mater. Sci. 55, 61-105. https://doi.org/10.1016/j.pmatsci.2009.08.001.

Verdier, M., Brechet, Y., Guyot, P., 1998. Recovery of AlMg alloys: flow stress and $\begin{array}{lllll}\text { strain-hardening } \quad \text { properties. } & \text { Acta } & \text { Mater. } & \text { 47, } & \text { 134. }\end{array}$ https://doi.org/10.1016/S1359-6454(98)00350-4.

Voorhees, P.W., 2006. Alloys: Scandium overtakes zirconium. Nat. Mater. 5, 435-436. https://doi.org/10.1038/nmat1663.

Wang, X.G., Han, G.M., Cui, C.Y., Guan. S., Jin, T., Sun, X.F., Hu, Z.Q., 2016. The dependence of Portevin-Le Châtelier effect on the $\gamma^{\prime}$ precipitates in a wrought Ni-base superalloy. Metall. Mater. Trans. A 47A, 5994-6003. https://doi.org/10.1007/s11661-016-3718-x.

Wang, X.G., Han, G.M., Cui, C.Y., Guan. S., Li, J.G., Hou, G.C., Zhou, Y.Z., Sun, X.F., 2019. On the $\gamma^{\prime}$ precipitates of the normal and inverse Portevin-Le Châtelier effect in a wrought Ni-base superalloy. J. Mater. Sci. Technol. 35, 84-87. https://doi.org/10.1016/j.jmst.2018.09.014.

Wert, J.A., Wycliffe, P.A., 1985. Correlation between S' precipitation and the Portevin-Le Chatelier effect in an Al-Li-Cu-Mg-Zr alloy. Scr. Metall. 19, 463-466. https://doi.org/10.1016/0036-9748(85)90114-0.

Xiao, L., Chen, D.L., Chaturvedi, M.C., 2005. Shearing of $\gamma^{\prime \prime}$ precipitates and formation of planar slip bands in Inconel 718 during cyclic deformation. Scr. Mater. 52, 603-607. https://doi.org/10.1016/j.scriptamat.2004.11.023.

Xu, S.S., Zhao, Y., Chen, D., Sun, L.W., Chen, L., Tong, X., Liu, C.T., Zhang, Z.W., 2019. Nanoscale precipitation and its influence on strengthening mechanisms in an ultra-high strength low-carbon steel. Int. J. Plast. 113, 99-110. https://doi.org/10.1016/j.ijplas.2018.09.009. 
Yang, F., Luo, H.W., Pu, E.X., Zhang, S.L., Dong, H., 2018. On the characteristics of Portevin-Le Chatelier bands in cold-rolled 7Mn steel showing transformation-induced plasticity. Int. J. Plast. 103, 188-202. https://doi.org/10.1016/j.ijplas.2018.01.010.

Yilmaz, A., 2011. The Portevin-Le Chatelier effect: a review of experimental findings. Sci. Technol. Adv. Mater. 12, 063001. https://doi.org/10.1088/1468-6996/12/6/063001.

Yoshinaga, H., Morozumi, S., 1971a. A Portevin-Le Chatelier effect expected from solute atmosphere dragging. Philos. Mag. 23, 1351-1366. https://doi.org/10.1080/14786437108217007.

Yoshinaga, H., Morozumi, S., 1971b. The solute atmosphere round a moving dislocation and its dragging stress. Philos. Mag. 23, 1367-1385. https://doi.org/10.1080/14786437108217008.

Yuzbekova, D., Mogucheva, A., Zhemchuzhnikova, D., Lebedkina, T., Lebyodkin, M., Kaibyshev, R., 2017. Effect of microstructure on continuous propagation of the Portevin-Le Chatelier deformation bands. Int. J. Plast. 96, 210-226. https://doi.org/10.1016/j.ijplas.2017.05.004.

Zavattieri, P.D., Savic, V., Hector Jr, L.G., Fekete, J.R., Tong, W., Xuan, Y., 2009. Spatio-temporal characteristics of the Portevin-Le Châtelier effect in austenitic steel with twinning induced plasticity. Int. J. Plast. 25, 2298-2330. https://doi.org/10.1016/j.jplas.2009.02.008.

Zhang, F., Bower, A.F., Curtin, W.A., 2012, The influence of serrated flow on necking in tensile specimens. Acta Mater. 60, 43-50. https://doi.org/10.1016/j.actamat.2011.09.008.

Zhang, Q.C., Jiang, Z.Y., Jiang, H.F., Chen, Z.J., Wu, X.P., 2005. On the propagation and pulsation of Portevin-Le Chatelier deformation bands: an experimental study with digital speckle pattern metrology. Int. J. Plast. 21, 2150-2173. https://doi.org/10.1016/j.ijplas.2005.03.017.

Zhang, Y., Liu, J.P., Chen, S.Y., Xie, X., Liaw, P.K., Dahmen, K.A., Qiao, J.W., Wang, Y.L., 2017. Serration and noise behaviors in materials. Prog. Mater. Sci. 90, 358-460. https://doi.org/10.1016/j.pmatsci.2017.06.004.

Zhang, S., McCormick, P.G., Estrin, Y., 2001. The morphology of Portevin-Le Chatelier bands: Finite element simulation for Al-Mg-Si. Acta Mater. 49, 1087-1094. https://doi.org/10.1016/s1359-6454(00)00380-3.

Zhemchuzhnikova, D.A., Lebyodkin, M.A., Lebedkina, T.A., Kaibyshev, R.O., 2015. Unusual behavior of the Portevin-Le Chatelier effect in an AlMg alloy containing precipitates. Mater. Sci. Eng. A 639, 37-41. https://doi.org/10.1016/j.msea.2015.04.094.

Zhemchuzhnikova, D., Lebyodkin, M., Lebedkina, T., Mogucheva, A., Yuzbekova, D., Kaibyshev, R., 2017. Peculiar spatiotemporal behavior of unstable plastic flow in an AlMgMnScZr alloy with coarse and ultrafine grains. Metals 7, 325. https://doi.org/10.3390/met7090325.

Zhemchuzhnikova, D., Lebyodkin, M., Yuzbekova, D., Lebedkina, T., Mogucheva, A., Kaibyshev, R., 2018. Interrelation between the Portevin-Le Chatelier effect and necking in AlMg alloys. Int. J. Plast. 110, 95-109. https://doi.org/10.1016/j.ijplas.2018.06.012. 